\title{
Adoption of Inflation Targeting in Sierra Leone: An Empirical Discourse
}

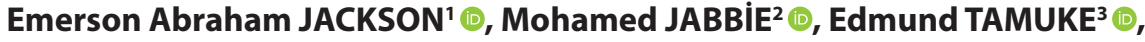 \\ Augustine $\mathrm{NGOMBU}^{4}$ (i)
}

\begin{abstract}
The main research question of this paper is to assess Sierra Leone's preparedness for adopting a fully-fledged or lite Inflation Targeting (IT) framework amid macroeconomic and structural bottlenecks experienced in the domestic economy. Several theoretical and empirical perspectives were reviewed to bring out cogent insights on the subject matter. With the use of the Unrestricted Vector Autoregression (VAR) model, relevant macroeconomic variables ranging from 2010Q2 to 2019Q4 were utilised to assess plausible outcomes, aided with some iterative shock impulses, variance decomposition, and historical decomposition, to explain the reaction of inflation to specific factors in Sierra Leone. The study outcome suggests that Sierra Leone as a supply-driven economy is inducing a high level of inflation on account of the pass-through effect of high prices to consumers in the domestic economy. This to a greater extent is undermining monetary policy management, which gives credence to the fact that authorities at the Bank of Sierra Leone should not switch to inflation targeting in the short and medium-term on the basis that monetary policy actions could instigate further price increases of goods and services, underpinned by weak real sector operations and a somewhat dollarized domestic market. At best, there is a need for BSL to continue its current policy methodology, while working in ensuring monetary policy actions are transparent and well communicated at all times to getting inflation to a single-digit.
\end{abstract}

Keywords: Inflation targeting, monetary policy, var, sierra leone JEL Classification: E31, E42, E52, E58
DOI: $10.26650 / J E P R 735604$

\begin{abstract}
'xxx, Research Department, Bank of Sierra Leone, Sierra Leone

${ }^{2}$ Research Economist, Independent Researcher and CFA Level 1 Candidate

${ }^{3}$ Research Economist, Research Department, Bank of Sierra Leone, Sierra Leone ${ }^{4}$ Research Economist, Research Department, Bank of Sierra Leone, Sierra Leone
\end{abstract}

ORCID: W.Z. E.J. 0000-0002-2802-6152;

M.J. 0000-0001-9082-6524;

E.T. 0000-0002-2320-6541;

A.N. 0000-0003-4677-5613

\section{Corresponding author/Sorumlu yazar: Emerson Abraham JACKSON, \\ Research Department, Bank of Sierra Leone, Sierra Leone \\ E-mail/E-posta: E-mail: ejackson@bsl.gov.sl}

\section{Submitted/Başvuru: 22.05 .2020 \\ Revision Requested/Revizyon Talebi: 22.06.2020 \\ Last Revision Received/Son Revizyon: \\ 22.06.2020 \\ Accepted/Kabul: 22.06.2020}

Citation/Atıf: Jackson, E.A., Jabbie, M., Tamuke E. \& Ngombu, A. (2020). Adoption of Inflation targeting in sierra leone: an empirical discourse. iktisat Politikası Araştırmaları Dergisi - Journal of Economic Policy Researches, 7(2), 21-50. https://doi.org/10.26650/JEPR735604 


\section{Introduction}

Inflation Targeting (IT) as a concept has become a common practice around the world, notably in many of the developed economies, some emerging market economies and more lately in the African continent (Svensson, 2010; Hammond, 2012; Taylor, 2019; Bleaney, Morozumi, and Mumuni, 2020). As a form of monetary policy instrument, which dates back to the Keynesian-monetarists debate on rules versus discretion (Saleem, 2010; Chaudhry and Chaudhry, 2005), IT framework is hinged on the independent/autonomous status of central banks and their actions to setting single-digit inflation target, exclusively from the concerns of other macroeconomic components like exchange rate, employment, wages, etc. (Debelle et al 1998). In practice, many researchers have sounded its praise for driving down inflation in an economy (Bernanke and Mishkin, 1997; Ball, 2010). As a monetary policy tool, IT is characterised by setting specific quantitative targets, above which inflation cannot exceed - in practice, central banks are particularly focused in instituting policies aimed at achieving single-digit inflation in the long run, while also being responsive to perturbed concerns in the short-run. As a guideline for its effective implementation, IT normally ensures that the monetary policy framework is specific about measures connected with accountability and transparency of operations (Aliyu and Englama, 2009; Savensson, 1999). Monetary Policy (MP) regime under IT framework can be perceived as a draconian measure, which is also likened to "constrained discretion" by many critics given the fact that central banks are not only required to set targets but ensuring the right instruments are applied in a bid to achieving the desired goal of subduing inflation (Aliyu and Englama, 2009; Fischer, 2000).

Despite the tough approach used by monetary policy authorities to implement IT framework, there are clear indications of its immense benefits to society at large - with the focus of IT geared towards stabilising domestic economies without compromising spillages of shocks, there is a real benefit of its impact being felt on real output. In the case of weak economies, there is the possibility that targets can easily ease economic pressures, through the use of specific instruments to bring inflation to a reasonable rate. As already addressed in the key elements, IT is a process that is easily understood, given the requirement of monetary policy authorities to become transparent through overt communication with the public. Amid the highlighted benefits, there is also some level of dangers attributable to the practice of IT framework - this involves the timeinconsistency trap, which central banks can easily fall into given the uncontrolled influence of perturbations. Such occurrences may occur domestically and globally as witnessed recently with the emergence of COVID-19 health pandemic (see Jackson, 2020a).

Specific to Sierra Leone, consideration given to adopting the IT framework needs thorough assessment given the country's macroeconomic quagmire and most importantly, the readiness of the Bank of Sierra Leone (BSL) to achieve agreed targets, which invariably 
is critical to ascertaining confidence in the domestic economy. In this regard, transitioning from the current monetary aggregate regime (with price stability being the main objective and supported by a suite of forecast models) to something new will require an accurate and robust assessment of the wider implications of such a policy shift across the different sectors of the economy (Jackson, 2020b; Jackson, 2020c; Lavally and Nyambe, 2019; Jackson, Sillah and Tamuke, 2018; Tamuke, Jackson and Sillah, 2018). In this regard, an understanding of the significance of quantitative indicators to support monetary policy decisions on the drive of controlling inflation hike is very critical in the process of exploring the possibility of adopting either a 'fully-fledged or lite' IT framework in addressing the long-term stability of the Sierra Leone economy.

Expounding further on the concepts, the former (fully-fledged IT) is based on a strict nominal anchor, normally single-digit inflation rate considered relevant in support of macroeconomic stability - such type of framework is suitable for countries with the sound financial environment, and coupled with central banks' transparency to standing accountable in affirming their commitments to set targets (Aliyu and Englama, 2009). Conversely, the latter (lite IT framework) is considered a medium or low profile approach pursued by economies characterised as fragile in terms of their macroeconomic structures, notably epitomized by weak fiscal position, high debt to GDP ratio, vulnerability to external shocks, weak monetary and financial systems, etc. (Aliyu and Englama, 2009: 9; Angeriz and Arestis, 2007) - such economies would normally resort to floating the exchange rate system, and backed by their preparedness to come to the public about targets, which are normally hard to achieve (Saleem, 2010).

Sierra Leone has featured prominently through economic and natural turbulences, notably Ebola around 2014-16, Mudslide in 2017, and commodity price shock in 2014; these are sufficient indications to saddle the country through bleak prospects of instituting affirmative policy stances capable of supporting long term stability in domestic price control measures. Generally speaking, central banks can manipulate monetary policy instruments in a bid to stabilise domestic output through affirmative action of its autonomous powers. For over decades in Sierra Leone, such autonomy status accorded in pursuit of addressing price stability objective was in some way meddled with as manifested in the almost collapsed state of notable (state-owned) commercial banks around 2016-18 and also, coupled with poor performance in real sector operations (Jackson and Jabbie, 2020). The dominance of supply-side influences in the domestic economy, for example, coupled with exchange rate concerns and the over-reliance of import of inelastic goods and services (for domestic consumption) have made it possible for import demand (for essential items like food and petroleum products) to dominate the domestic market and inevitably weakening the BSL's effort in enforcing its core mandate of achieving single-digit inflation (Jackson, Tamuke and Jabbie, 2019; Bangura, Caulker and Pessima, 2012; Kallon, 1994). 
Amid some of the highlighted issues prevailing in the domestic economy, and coupled with critics' voices about the downside of IT framework, previous and present authorities at the Bank of Sierra Leone (BSL) have worked through various hurdles in ensuring the core objective of price stability is addressed through a review of relevant sections of the BSL Acts. Notable revision includes the BSL Act of 2011, which brought in the Monetary Policy Committee (MPC), with its unique focus of incorporating an econometric model approach to forecasting inflation dynamics and more lately, the BSL Act of 2019 Act, which finally reinforced the autonomous status of the bank in a bid to regulate irregularities concerned with forex trading and many more. Despite the BSL's effort in effecting specific policy measures to address inflation hike, inflation is still manifesting itself as a serious threat to economic stability and the sustained decent well-being for citizens in the economy, with a notable highlight of a $20.20 \%$ surge in inflation around March 2017. The Sierra Leone economy is likely to continue in the pathway of perturbed economic threats throughout 2020 and beyond on account of structural bottlenecks in the real sector, which has become more apparent amid COVID-19 global calamity - this will also have implications on the BSL's effort to utilise available instruments to curb inflation at the desired single-digit rate in the medium and long term.

Given the dichotomy revolving around the good and downside of the IT framework, the process can be thought of as a move in the right direction, which is aimed at supporting a balanced and stable economic well-being for citizens in economies where it has already being implemented. In a bid to explore our knowledge quest on the scope of IT adoption in Sierra Leone, which is currently saddled with structural concerns, the authors have set themselves the challenge of exploring an answer to the highlighted question: Is the Sierra Leone economy well prepared to adopt a full-fledged or lite IT framework given macroeconomic bottlenecks connected with an almost unproductive real sector?

The motivation behind this study is to assess the preparedness of the BSL in its approach to policy formulation geared towards setting the country on a firm pathway of achieving single-digit inflation as part of its medium to a long-term goal, which will also be a welcoming achievement towards being part of the Economic Community of West African States (ECOWAS) single-currency project, earmarked as the ' $E C O$ '. Such an approach is earmarked for empirical testing through effective utilisation of a justified econometric model and backed by carefully selected macroeconomic variables - with consideration highly focused on monetary, demand and supply-side driven variables and their influences in instigating inflationary threat in the domestic economy. To answer the aforementioned question on the adoption of a fully-fledged or lite IT framework in Sierra Lone for medium and long-term price control, we set the following key milestones or objectives highlighted below:

- To utilise appropriate econometric methodology for investigating the quantitative relationship between inflation, monetary policy instrument, and the output gap. 
- To investigate the possibility of a fully-fledged or IT-Lite framework for the attainment of single-digit inflation in the medium and long term.

- To proffer recommendations for policy implementation by the BSL in its stride to attaining single-digit inflation.

This is perceived as a unique study and in fact, the first attempt at exploring Sierra Leone's preparedness on the journey to implementing an IT framework (fully-fledged or lite), in a bid to supporting sustained and decent living conditions for citizens in the economy. The Vector Autoregression (VAR) model is utilised; despite its weak theoretical foundation, it has proved very popular by economists in the exploration of decisions surrounding the implementation of IT framework (Soders torm, 1999; Aliyu and Englama, 2009; Saleem, 2010). Data for this study was generated from different sources, notably the Bank of Sierra Leone Data Warehouse System and WDI, spanning from 2010Q2 to 2019Q4.

The rest of the paper is therefore structured as follows: Section two focuses attention on Stylized facts of Inflation dynamics in Sierra Leone, while section three addresses the literature review, sub-sectioned into theoretical and empirical reviews. Section four covers information about the methodology and empirical results, while Section five provides a clear analysis of the empirical results. Section six addresses the model robustness and finally, section seven concludes with some pointers for policy recommendation.

\section{Stylised Facts About Inflation Dynamics and It-Rule Readiness In Sierra Leone}

The Bank of Sierra Leone seems to have adopted an approach to a market-based instrument of monetary policy since its inception in 1964. The underlying objective of such an approach as indicated in the 1963 Act was constructed on the tenacity of maintaining monetary stability. Series of amendments have been made on the monetary policy framework to achieve macroeconomic stability in the domestic economy. Between 1963 and 1999, the BSL utilised a combination of direct and indirect monetary policy instruments, which include reserve requirement, selective credit control, and moral suasion in terms of strategizing on its main focus of maintaining macroeconomic stability in the country (Lavally and Nyambe, 2019).

The revised BSL Act of 1999 emphatically made it possible for the Price Stability objective to be seen as the way forward on the bank's approach to utilising its mandate to focus attention on the well-being of citizens. Moving on from this period, the Amendment of the 2000 BSL Act then gave way to the 2011 BSL Act, which ardently paved the way for the formation of a Monetary Policy Technical Committee (MPTC) mandated to support the bank's forward-looking approach in addressing its core mandate of maintaining price 
stability and precisely, single-digit (Mansaray and Swaray, 2012). Over time, the nomenclature of MPTC was later re-casted to the Monetary Policy Committee (MPC), with the Governor and Deputy Governor(s $)^{1}$ as automatic members, headed by the Governor, and five additional members of high standing in society (three appointed by the Governor and the remaining two by the Minister of Finance). This committee is mandated to discharge the BSL's role in maintaining low inflation, informed by dedicated research activities, which notably involves the use of econometric models to forecast short and medium-term inflation. Inflation forecasting at the BSL has evolved, with the incorporation of a suite of models, involving a range of macroeconomic variables (Exchange Rate, GDP, Government Expenditure, etc.), with Consumer Price Index (CPI) being the target variable to support the MPC's decision in its stride to maintaining price stability (see the highlight of outputs on model utilisation - Bangura et al, 2012; Jackson, 2018; Jackson and Tamuke, 2018; Jackson, Sillah and Tamuke, 2018; Jackson, Tamuke and Jabbie, 2019). Inflation forecasting is an essential part of the quantitative target of IT framework (based around single-digit inflation) and more so, in allaying economic agents' confidence about the stable direction of an economy (Debelle, et al, 1998).

In a bid to become forward-looking, the 2019 BSL Act was very much targeted in addressing the autonomous element of the BSL, with powers vested on the Bank's authority to execute its elements. In line with the qualitative approach of IT framework, management at the bank has already made a head start, which in a way could be seen as mirroring the ITlite framework, with a notable pronouncement of its MPC statements as a means of transparency to the public. The revised Bank of Sierra Leone Act of 2019 has now made it apparent for the independent status to be utilised, which encapsulates both monetary and financial independence in decision making that bothers around price and financial stability (BSL, 2019a and 2019b). Given such a decision, an immediate action to address expected concerns around COVID-19 was pronounced and immediately published (via various national media outlets) to calm public worries about the impact on well-being and its impact on macroeconomic and financial stability.

Section 47(1) of the BSL Act of 2019 also made it clear for the bank to be consulted on the determination of a foreign exchange regime, which also supports its mandate for maintaining price stability. The effectiveness of the bank's status as an independent/ autonomous institution is continually affirmed through its power to simplify the transmission of Monetary Policy Rates (MPRs), thus making it possible for published monetary policy

\footnotetext{
${ }^{1}$ With the revised BSL Act of 2019, there is a scope for the appointment of a second Deputy Governor, whose role will be focused on Financial Stability, while first Deputy Governor charged with the responsibility of managing economic research and other such duties as would deem necessary under the new structure.
} 
statements to highlight concerns around price and financial stability. Over the years, there has been a relaxed state of transmission action on account of commercial banks' reluctance to transmit policy rates to lenders and also, the frequent meddling into the strategic governance at the bank - instead, what has happened is a situation where banks have been seen to hike their lending rates, while at the same time hedging risks of high default on the 364-days Treasury Bills market.

Figure 1 below provides a clear illustration of the direction and relationship between Monetary aggregate variables like Broad Money (M2) with CPI and Exchange Rate, considered vital influences in affecting prices.

Figure 1. Growth in Selected Macroeconomic Indicators

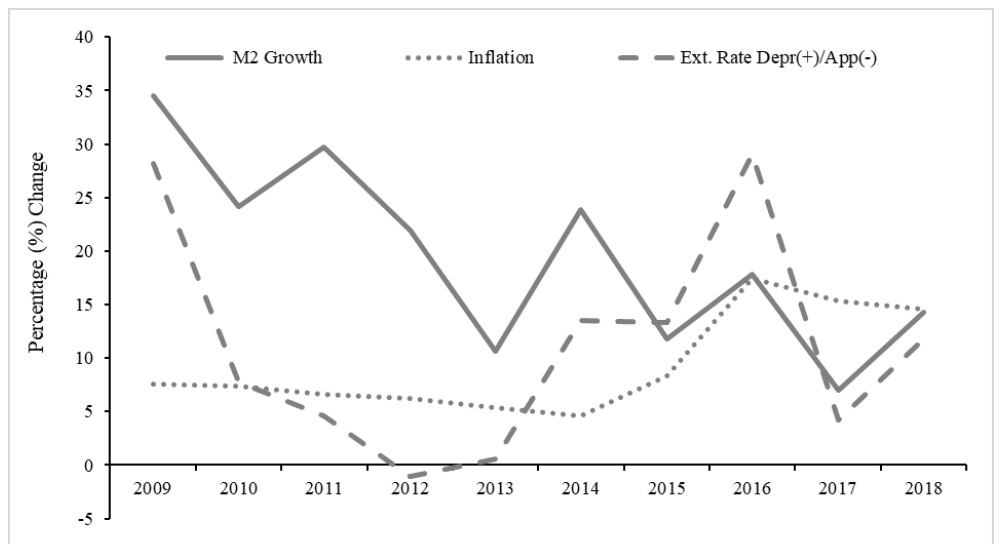

Source: BSL Data Warehouse \& Authors' calculation

Figure 1 above shows how the selected indicators, which are considered incredibly significant in the maintenance of price and financial stability in Sierra Leone moved over time. One clear graphical inference that can be gleaned is that for the most part, there is a high degree of co-movements amongst the variables - this is statistically proven in the correlation matrix provided in Table 3. This shows a reasonable degree of connection between the annual growth of CPI with M2 as well as with Exchange Rate. Policy practitioners and several research pundits believe that the exchange rate is a significant determinant of price movements in Sierra Leone (Jackson, 2020; Bangura, Caulker and Pessima, 2012) - a belief rooted in the rate of high dependence on imports. This is manifested in the chart were periods of high exchange rate depreciation are accompanied by an increase in inflation and vice versa, particularly around the years 2009 and 2016. This presents a worrying concern if the IT framework is to be utilized as a tool for effecting price stability in the country. 
Critical to the objective of achieving price stability, the BSL is now seen to be adopting a second objective (as expressed in the BSL Acts 2019), which is geared towards maintaining financial stability. This therefore now makes it a challenge for the bank to focus attention on its dual role of anchoring price and financial stability. The experience of excessive-high NPLs as witnessed in the recent past is a clear example of how the crisis in the financial sector has proved problematic for the BSL in anchoring its objective of price stability. While it is thought that inflation targeting can be good at addressing inflationary pressures in an economy, some researchers have expressed its downside as a build-up to financial instability given its narrow focus in singling out price stability as the main focus (Taylor, 2007; Svensson, 2010; Frankel, 2012; Araújo et al, 2020). In a bid to quell such criticism or worries, the appointment of a second Deputy Governor as mandated in the revised BSL Act of 2019 has now made it possible for the role of financial stability to be left under the purview of the appointee, through the support of the operational arm of the Financial Policy Committee (FPC) ${ }^{2}$. Such pivotal appointment will, therefore, make it possible for the revised 2019 BSL and Banking Acts to be judiciously utilised in a bid to implement the BSL's autonomous status in pursuance of the effort to maintaining single-digit inflation target, through continuous monitoring of the system against set quantitative and qualitative criteria, vis-à-vis inflation forecasting and regular public announcements respectively.

\section{Literature Review}

\subsection{Theoretical Approach}

As expressed by Debelle et al (1998), inflation is said to evoke bad news about the state of decent well-being - it erodes the possibility of people's propensity to save, while also a turn-off to investments, stimulate capital flight, inhibit growth, induce nightmare to economic planning and in the most extreme case, insight social and political unrest in a country. Because of these atrocities, governments across the world economy are continuously setting policy measures to keep inflation at a reasonable rate in a bid to support decent wellbeing for citizens. Such an approach to a simplistic means of setting inflation to a low level is now sufficiently well addressed and hence, most economies have gone the extra mile of enforcing price stability targets, to a single-digit level. Some economists have argued against the trade-off, which normally conflicts with employment and output (Ball and Sheridan, 2005). On this note, the concept of Inflation Targeting can be construed as "a monetarypolicy strategy that is characterized by an announced numerical inflation target, and

\footnotetext{
2 The Financial Policy Committee (FPC) is mandated to operate on a parallel line with the long-existing Monetary Policy Committee (MPC) - there is a clear-cut dichotomy, which means that the FPC will also be expected to embark on research ventures in a bid to surveillance risks to the financial system, which is critical in complementing the role of the MPC in maintaining a consistently low domestic inflation.
} 
implementation of monetary policy that gives a major role to an inflation forecast and has been called forecast targeting, and a high degree of transparency and accountability (Svensson, 2010)".

Based on the above discourse, IT mechanism according to Mishkin (2001: 1) can be pursued on the line of five main elements: (i) medium-term announcement of inflation targets to the public, (ii) institutional commitments relating to the primary goal of price stability, (iii) policy instruments comprising of macro-variables, not only restricted to monetary aggregates or exchange rate, (iv) transparent means of communication to the public about planned objectives and strategy by monetary policy authority, and last, but not least, (v) accountability of central banks in justifying how objectives are to be achieved.

IT framework is considered particularly important, both for developed and emerging market economies given the role it plays in ensuring effective planning by governments is set in place to address medium to long-term economic sustainability. Given Alan Greenspan's explanation of the concept, the IT framework is perceived to be one in which the household would not need to take cognisance of price dynamics as long as it is within a target band of 0 $-3 \%$ (Mishkin, ibid). There is a contrary view to the established notion of IT framework being set to Zero, which invariably is viewed as a form of disincentive to supporting high employment in an economy - in which case, the outcome would normally result in disinflation, with the possibility of spearheading financial instability (Akerlof, Dickens and Perry, 1996).

Myriad of studies have been undertaken to address the benefits of IT framework in an economy - such benefits are typically attested through persistent single-digit inflation rates announced by central banks in developed economies, where IT framework have been implemented, notably New Zealand as the first to take up IT framework in the early 1990s, followed by Canada in 1991, and the United Kingdom and Sweden in 1992 and 1993 respectively and many more (Mishkin, 2000; Roger, 2009; Svensson, 2010: 7). This phenomenon cannot be overemphasized given the dangers inflation creates on the wellbeing of citizens in an economy. IT framework is built on a sound system of addressing medium to long-term certainty for macroeconomic stability. In contrast to the pegged exchange rate system, the IT framework allows monetary policy to direct attention to domestic concerns, with a higher scope of responding to domestic shocks (Mishkin, 2000: 2-3; Truman, 2003). The fact that IT framework is set on given criteria (both qualitative and quantitative) meant that the public should always be kept abreast about the direction of policy instruments that best suit the purpose of maintaining a desirable inflation target rate (Mishkin 2001; Debelle et al, 1998; Frederic Mishkin and Adam Posen, 1997). The use of quantitative targets (pursued through forecasting mechanism) normally makes it possible for 
central banks to avoid issues connected with time-inconsistency trap; central banks are normally able to steer political debates in the direction of long-term objective that keeps inflation at a consistent single-digit level, which is quite different from the expectation of raising output or lowering unemployment (Mishkin, 2000; Ball and Sheridan, 2005; Svensson, 2010: 11).

Given the success story of countries that have adopted IT regime as a framework, some school of economic thoughts has critiqued the process based on the view that it is geared towards neglecting supply-side factors in an economy while being heavy-weighted on price stabilisation - the overall outcome of this can sometimes result in supply-side and balance of trade shocks, but the overall benefits of stabilising prices seem to overshadow that of critics' concerns. Studies conducted by Ghosh and Phillips (1998) and Bruno and Easterly (1995) have outlined the ramifications of inflation. Despite the need to set criteria on which IT framework is to be discharged, there is no indication that the framework can prevent fiscal dominance and more importantly, emphasis on flexibly exchange rate mechanism can in itself spearhead financial instability (Mishkin, 2000; Mishkin, 1999; Bernanke et al, 1999). Also, Krueger (2005) elaborated on the impact of inflation in distorting resource allocation in the economy, with the ultimate ramification in generating macroeconomic imbalances.

Despite its negative outcry, the IT framework is gaining credence, specifically in emerging markets and many developed economies where it is proving to be of relevance in addressing macroeconomic stability (Mishkin, 2000). A notable example of this is a study carried out by Loayza and Sota (2002), which proved that countries in the European Monetary Union (EMU) are performing better with the adoption of the IT framework. The end goal for adopting the IT framework is to achieve a low inflation rate, which is mostly geared towards a single-digit outcome, normally perceived as a catalyst for macroeconomic stability while reducing uncertainties in the minds of investors and economic agents.

Inflation targeting regime as championed by central banks around the globe seem to have thrived well on its main anchor / primary goal, which is price stability, and this requires strong institutions and governance. The practicality of IT framework is also gaining traction in the African sub-region as exemplified in Table 1 below, with notable examples in economies like South Africa (commenced in 2000) and Ghana, informally adopted in 2002, with full-fledged adoption in 2007 and up till present the central bank has been able to meet its point and tolerance limit ( \pm 2 points) in a bid to achieve its single-digit target. The most and recent entrant to the IT framework in the Sub-Saharan African (SSA) region in Uganda, which was adopted by the central bank in 2011. Despite the fragile state of the Ugandan economy at the time, particularly concerning its shallow financial markets, volatile exchange rate and supply-side shocks (supposedly the critical influence on inflation and its accurate 
forecasting), IT framework was still considered as a possible means to supporting the objective of stable price mechanism given the confidence of authority on the 'operational independence ${ }^{3}$ of the central bank (Brownbridge and Kasekende, 2018). It is worth noting that, while price stability is treated as the primary target for nearly all central banks in achieving low inflation, some have also factored secondary targets like the effective operation of the banking system, high employment rate, and sustainable economic growth notable examples include countries like South Africa, Ghana and the United Kingdom and some of these are done either independently by Government / Central Bank or jointly by both government and central bank (Hammond, 2012; Araújo et al, 2020).

Table 1: Key Features of IT Framework in Three African Economies

\begin{tabular}{|c|c|c|c|c|c|}
\hline $\begin{array}{c}\text { Country and Date } \\
\text { of Adoption }\end{array}$ & Legal Mandate & Target Horizon & $\begin{array}{c}\text { CB } \\
\text { Operational } \\
\text { Independence }\end{array}$ & $\begin{array}{l}\text { Target } \\
\text { Type and } \\
\text { Measure }\end{array}$ & $\begin{array}{l}\text { Target } \\
\text { Set by }\end{array}$ \\
\hline $\begin{array}{c}\text { South Africa - Feb- } \\
\text { ruary } 2000\end{array}$ & $\begin{array}{l}\text { Protection of currency } \\
\text { value and sustainable } \\
\text { economic growth. }\end{array}$ & Continuously & Yes & Range; HCPI & G \\
\hline $\begin{array}{c}\text { Ghana - informally } \\
\text { in } 2002, \text { with full } \\
\text { adoption in May } \\
2007\end{array}$ & $\begin{array}{l}\text { Price stability, econom- } \\
\text { ic growth, and effective } \\
\text { operation of banking } \\
\text { and credit system. }\end{array}$ & Medium-term & Yes & $\mathrm{P}+\mathrm{T} ; \mathrm{HCPI}$ & $\mathrm{G}$ and $\mathrm{CB}$ \\
\hline $\begin{array}{l}\text { Uganda - July } \\
\text { 2011(IT Lite) }\end{array}$ & Price stability & $\begin{array}{c}\text { Medium-term } \\
\text { (Once every two } \\
\text { months) }\end{array}$ & Yes & $\mathrm{P}+\mathrm{T}$; HCPI & $\mathrm{CB}$ \\
\hline
\end{tabular}

Source: Extracted from Hammond (2012) and Brownbridge and Kasekende (2018); CB - Central Bank, G - Government, HCPI - Headline Consumer Price Index, $\mathrm{P}+\mathrm{T}-$ Point with tolerance band

Given the overall research question of this paper, economies can opt to adopt a fully-fledged or IT lite framework depending on the readiness of systems, particularly with the independent status accorded to central banks. A notable example of central banks that are thought to be anchoring low inflation, which is mirrored on the IT framework includes the United States Federal Reserves and the European Central Bank (Jahan, Online). Distinctively, such central banks are not obliged to make public announcements of numerical targets like the published forecast results produced in the case of fully-fledged IT economies. A lite IT framework or disguised IT-lite framework simply attests to the fact that processes would need to be well researched, with all relevant criteria set in place or sampled over a given period, before coming public about the need to take up IT framework. As a matter of caution, Bernanke and Mishkin (1997) advised central banks to focus

\footnotetext{
${ }^{3}$ This as a process made it possible for the establishment to separate the role of the monetary operations (with the interest rate set as the operational target and the published communication to the public) from that of the fiscal operational discharge, which is normally the responsibility of dedicated fiscal authority (Brownbridge and Kasekende, 2018).
} 
attention on indicators that are likely to trigger future inflation in their pursuit of adopting an IT framework. Pui (2003) also noted that the IT framework does not always factor the social welfare implications given the fact that central banks are mostly focused on adjusting expansionary and contractionary monetary policy measures in view of achieving an overall single-digit target.

\subsection{Empirical Review}

Since the main focus of this paper is to empirically assess the future adoption of IT framework for Sierra Leone, it was deemed fit to devote attention to reviewing published and relevant empirical works in the line of utilising appropriate methodology to achieve the desired aim and objectives. We have noted evidence of mixed findings connected with the reviewed papers. However, despite contrasting outcomes, the literature review is an eyeopener to our focus, concerning the rationale for the identified variable choices. The undermentioned empirical highlights provide information about IT framework researchers from across the world have embarked on in a bid to assess its overall impact on central banks' motive for stabilising inflation to as reasonable a single-digit target.

Svensson (2000) examines inflation targeting for a small open economy with forwardlooking aggregate supply and demand with micro-foundations. In this, he also adopted stylized realistic lags in the different monetary-policy transmission channels that were utilised. The paper took an approach that compares strict and flexible targeting of CPI and domestic inflation, while also focusing attention on the IT reaction functions and the Taylor rule. The outcome proved that Flexible CPI-inflation targeting does not limit the variability of CPI inflation, but also shows variability in the output gap and the real exchange rate. It also shows that negative productivity supply shocks and positive demand shocks have similar effects on inflation and the output gap, which induces similar monetary policy responses.

Gottshalk and Moore (2001) undertook a study to show the link between monetary policy instruments and Inflation in Poland using the VAR (Vector Auto Regression) model. They found out that the exchange rate was of greater significance to output and prices, but inflation and interest rate were found to have produced a weak relationship. In the same vein, another study was done by Christofferson, Solk, and Wescott (2001) in Poland and their outcome shows that Poland is indeed ready to implement the inflation-targeting framework.

Carare et al (2002) set the pace in their paper to explore the full scope of inflation targeting, while at the same time, making it possible for countries seeking to adopt some of the measures in a bid to exploring possible fully-fledged approach shortly as conditions may permit. In this, they analysed the four strands of IT framework, which incorporate "(i) central bank inflation objective and accountability; (ii) the separation of monetary policy from fiscal operations that are supported by strong external position; (iii) stable and 
developed financial system; and finally, (iii) the subjection of exchange rate objective to inflation target". The success of the highlighted strands is normally proved successful through coordinated efforts between governments and central banks.

In contrast to the findings produced by Christofferson, et al (2001) in Norway, Bakradze, and Billmeier (2007) investigated the possibility of Georgia's readiness to adopt an IT framework using a baseline VAR model. The outcome shows that Georgia was not ready for reasons due to institutional weaknesses (multiplicity of potentially conflicting goals) in the system, while it was thought that monetary policymaking in Georgia lacks as a reliable indicator of the monetary policy stance.

Heintz and Ndikumana (2011), set out to examine in their study, the question of whether inflation-targeting monetary policy is an appropriate framework for Sub-Saharan African countries. The paper presented an overview of inflation targeting, with a review of the justification for the regime and a summarised critique of the IT system - the outcomes showed that monetary policy responses to inflation to a greater extent is dependent on the source of the identified inflationary pressures. In this, they utilised dynamic panel data to determine the results, with a discussion of the implications of Inflation Targeting in the region. Discussion from the outcomes was very extensive for Ghana and South Africa that have so far adopted an Inflation Targeting strategy. In conclusion, alternative approaches to monetary policies and the institutional constraints faced by Sub-Saharan African economies were discussed as a way of allowing central banks to play a greater role in the developmental process.

Hammond (2012) also made an effort to compile a handbook on state of the art of IT framework by taking account of 27 of the countries that were already in fully-fledged adoption and also, with some others that were in the process of moving in that direction. Individual country data made it possible for analysis to be explored about the design features of the framework - the outcome did not only limit its findings to the quantitative criteria but also extended its analysis to exploring qualitative processes associated with legal processes, institutional and accountability arrangements and the communication strategies for the announcements of quantitative targets.

Kelikume and Evans (2015) pursued a study that builds around issues for Nigeria, which is the dilemma of two possible nominal anchors: exchange rate pegging or inflation targeting. The study utilised time-series data and with the aid of Granger Causality test and impulse response functions, the results from the empirical analysis showed that inflation in Nigeria is highly sensitive to exchange rate and interest rate, while economic growth is highly sensitive to exchange rate and inflation. The causation from the real exchange rate to economic growth seems to be stronger than the causation from inflation to economic growth, which indicates 
that the exchange rate is a strong determinant of economic growth in Nigeria, more highly than the focus placed on inflation. It is, therefore, noted that because of such an outcome, inflation targeting will not be a preferred choice to exchange rate targeting in Nigeria as a policy alternative, which has important implications for monetary policy conduct in Nigeria.

Bleaney et al (2020) investigated the poor conduct of monetary policy in Ghana, which normally shows that inflation remained persistently high, even though the IT regime has been in operation since 2007 . The study investigated whether the poor conduct of monetary policy is responsible for such high inflation outcome, which came out not to be true. Monetary policy reaction functions from the study are like those estimated for countries with successful monetary policies, while in addition, interest rates respond as theoretically expected with the presence of inflation shocks.

Given the above literature review extracts, our focus is to utilize an appropriate methodology to assess the possibility of adopting a fully-fledged or lite IT framework in Sierra Leone, with suitable time-series data that captures the entirety of Sierra Leone's macroeconomic structure against set measures/criteria.

\section{Methodology and Empirical Analysis}

\subsection{The Econometric Model}

The model specification for this paper is based on the popularized version of the VAR concept by Christopher Sims (1986; 1980), which is expressed in Equation 1 below. According to Brooks (2008), a Vector Auto-regression (VAR) is a systems regression model that comprises both univariate time series and simultaneous equations models in which all variables are treated as endogenous.

$$
Y_{t}=A_{t} Y_{t-1}+\cdots A_{p} Y_{t-p}+\beta X_{t}+\varepsilon_{t} \quad \text { Eq. } 1
$$

Where:

$$
\begin{aligned}
& Y_{t}=\mathrm{k} \text { vector of endogenous variables } \\
& X_{t}=\mathrm{d} \text { vector of exogenous variables } \\
& \varepsilon_{t}=\text { the vector of innovations }
\end{aligned}
$$

$A_{t} \ldots A_{p} ; \beta=$ matrices of estimated coefficients.

Assuming some form of the contemporaneous relationship existing between the variables, the parsimonious ordering can be arranged as shown in the vector of equations below (Warburton and Jackson, 2020): 


$$
\begin{array}{ll}
G_{t}=\alpha^{i}+\sum_{j=1}^{k} \emptyset_{j} Y+\sum_{j=1}^{k} \gamma_{j} G_{t-j}+\sum_{j=1}^{k} \lambda_{j} E_{t-j}+\sum_{j=1}^{k} \varphi_{j} C_{t}+\sum_{j=1}^{k} \omega_{j} \pi_{t-j}+\mu_{2 t} & \text { Eq. } 2 \\
C_{t}=\alpha^{i i}+\sum_{j=1}^{k} \emptyset_{j} Y_{t-j}+\sum_{j=1}^{k} \gamma_{j} G_{t-j}+\sum_{j=1}^{k} \lambda_{j} E_{t-j}+\sum_{j=1}^{k} \varphi_{j} C_{t}+\sum_{j=1}^{k} \omega_{j} \pi_{t-j}+\mu_{4 t} & \text { Eq. } 3 \\
Y_{t}=\alpha^{i i i}+\sum_{j=1}^{k} \emptyset_{j} Y+\sum_{j=1}^{k} G_{t-j}+\sum_{j=1}^{k} \lambda_{j} E_{t-j}+\sum_{j=1}^{k} \varphi_{j} C_{t}+\sum_{j=1}^{k} \omega_{j} \pi_{t-j}+\mu_{1 t} & \text { Eq. } 5 \\
E_{t}=\alpha^{i v}+\sum_{j=1}^{k} \emptyset_{j} Y_{t-j}+\sum_{j=1}^{k} \gamma_{j} G_{t-j}+\sum_{j=1}^{k} \lambda_{j} E_{t-j}+\sum_{j=1}^{k} \varphi_{j} C_{t}+\sum_{j=1}^{k} \omega_{j} \pi_{t-j}+\mu_{3 t} & \text { Eq. } 6 \\
\pi_{t}=\alpha^{v}+\sum_{j=1}^{k} \emptyset_{j} Y_{t-j}+\sum_{j=1}^{k} \gamma_{j} G_{t-j}+\sum_{j=1}^{k} \lambda_{j} E_{t-j}+\sum_{j=1}^{k} \varphi_{j} C_{t}+\sum_{j=1}^{k} \omega_{j} \pi_{t-j}+\mu_{5 t} & \text { Eq. } 7
\end{array}
$$

Where: $Y_{t}, G_{t}, E_{t}, C_{\mathrm{t}}$, and $\pi_{\mathrm{t}}$ are endogenous variables in the system

$$
\text { - } Y=\text { Output Gap A }
$$

- $G=$ Government Expenditure, which typifies a measure of fiscal dominance

- $E=$ Nominal Exchange Rate

- $C=$ Broad Money

$$
\pi=\text { Inflation }
$$

\subsection{Summary Statistics and Variable Description}

To inspect the statistical features as well as trend patterns of the observed variables, data plots, and summary statistics were generated in their log form - five variables were utilized for the study, drawn from CPI (the main target variable, a proxy for Inflation), monetary (Broad Money -M2), fiscal (Government expenditure), supply and demand-side factors (proxy by Output Gap and Exchange Rate respectively). The data plots indicated that at levels, some of the variables were growing at a somewhat constant rate, while some displayed cyclical patterns. Moreover, the plots showed no prominent outliers in most of the variables under consideration, except for the output gap. The summary statistics revealed the average growth rate of all the variables as represented by their means, which were not too different from their respective medians, indicating the absence of outliers in most of the variables (since the median is not vulnerable to outliers). Moreover, the ranges as indicated by the maximum and minimum values further confirmed the absence of outliers in most of the variables. In addition, the standard deviations indicated minimum variability around the measures of central tendency, while the skewness, kurtosis, and Jarque-Bera statistic reflected that most of the variables indicated a relatively normal distribution. Details of the summary statistics are in Appendix 1. 
Figure 2. Variables in their Log Format
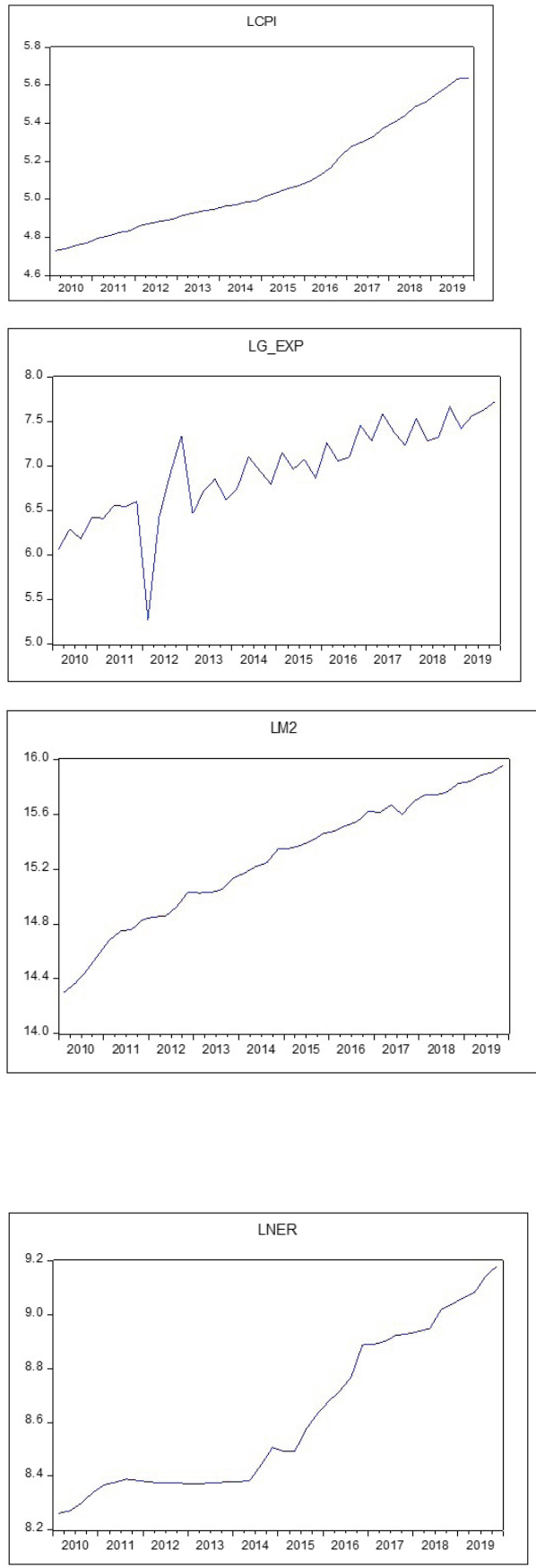

Figure 2A (LCPI): This variable is used as a proxy for Inflation, and it measures the weighted average of a basket of traded goods and services within the economy. The chart reflects that inflation in Sierra Leone has maintained a somewhat deterministic trend over the study period. This is the focus of the study, given that changes in this variable have ramifications for price stability and monetary policy efficacy.

Figure 2B (LO_EXP): This expresses government expenditure, which is treated as a proxy for the impact of fiscal control in this study. An extremely high fiscal dominated economy in which productivity is considered extremely low, like Sierra Leone, can be at high risk of inducing pressures on domestic prices.

Figure 2C (LM2): This is Broad Money (M2), which explains the total money supply in the economy. This variable is directly under the control of the central bank, which is used as the intermediate target under the monetary aggregate targeting regime. It is one of the tools the Bank uses to ensure a sound financial system, which is very essential to support a well stable price control mechanism. Money issued out by commercial banks is said to create an expansion of bank deposits; in a situation where this is inducing high appetite of consumers to spend, then central banks would be obliged to utilise relevant instruments to claw-back such excesses from the system in a bid to control the possibility of price escalation. In a well-developed economic system, monetary policy instrument utilised to curtail spending habit formation seem to work well under positive output-gap conditions.

Figure 2D (LNER): This is the nominal exchange rate of the Leone to the US Dollar, which is extremely critical in supporting a well-balanced system of price control in the country. On the whole, a country's exchange rate is partly dependent on the extent of its domestic production, particularly in reducing high dependence on the import of goods and services for basic domestic consumption. Where domestic productivity and earnings from exports are low, there is a high scope for foreign exchange demand to outweigh supply, with the eventual impact being the pass-through of exchange rate depreciation to domestic prices. 


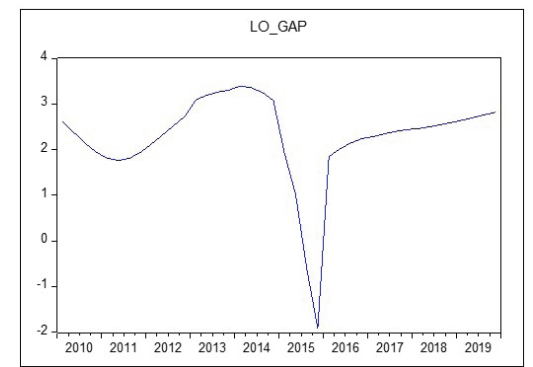

Source: EVIEWS Output
Figure 2E (LO_GAP): This is the difference between the actual output of an economy and the maximum potential output of an economy expressed in percentage terms of gross domestic product (GDP). In the real term, the output gap of a country can either prove to be positive or negative; the former (positive) proposes that an economy is outstripping productive expectations given that its actual output is higher than that which is expected as the maximum capacity. On the other hand, a negative output gap proposes that actual economic output is below a country's full potential output.

\subsection{Estimation Procedure and Empirical Results}

\subsubsection{Unit Root Test}

The first step in the estimation is to test each variable for Unit Root and to achieve this, we have specified the Augmented Dickey-Fuller (ADF) expression as shown in Equation 7 below - using the Schwarz Bayesian Criterion (SIC) as a basis for determining the number of lags to include:

The specification of the ADF is shown below, with results shown in Table 1.

$$
\Delta y_{t}=\beta_{1 t}+\beta_{2 t}+\alpha_{1} \sum_{i=1}^{m} \Delta y_{t-1}+\varepsilon_{t} \quad \text { Eq. } 7
$$

Where: $\Delta y_{t}=$ this is the first difference of the series $y_{t}$

$Y_{t}=$ is the individual time series

$\varepsilon_{t}=$ this is the white noise error term

$\mathrm{m}=$ the 10 ag order,

$\mathrm{t}=$ linear tren

$\beta=$ constant

Table 2: Augmented Dickey-Fuller (ADF) Test: Schwarz Bayesian Criterion (SBC).

\begin{tabular}{lcc}
\hline Variable & Level (I (0)) & First Diff. (I (1)) \\
\hline LCPI & -0.287626 & $-4.192365^{* *}$ \\
LM2 & -2.376566 & $-4.166847^{* * *}$ \\
LNER & 1.667463 & $-4.392721^{* * *}$ \\
LO_GAP & -2.449066 & $-5.741227 * * *$ \\
LG_EXP & -0.336347 & $-6.685110^{* * *}$ \\
\hline
\end{tabular}

Note: $* * * \& * *=1 \% \& 5 \%$ significance

Results from the ADF unit root test indicate that all the variables are non-stationary at levels but became stationary after first differencing at the one percent level of significance. Achieving stationarity after first differencing meant that the null hypothesis of the variables exhibiting unit root was rejected. 


\subsubsection{Correlation}

Generating the correlation matrix helped in identifying the type and extent of the relationship existing between and within the observed variables. It revealed the existence of a strong and positive relationship between and within the consumer price index (LCPI), money supply (LM2), the nominal exchange rate (LNER), and government expenditure (LG_EXP). However, a weak but positive relationship was found to exist between Output Gap (LO_Gap) and the other variables. This is captured in the table below.

Table 3: Correlation Matrix.

\begin{tabular}{lccccc}
\hline & LCPI & LG_EXP & LM2 & LNER & LO_GAP \\
\hline LCPI & 1.000000 & 0.820573 & 0.936411 & 0.981095 & 0.091439 \\
LG_EXP & 0.820573 & 1.000000 & 0.858347 & 0.805237 & 0.069418 \\
LM2 & 0.936411 & 0.858347 & 1.000000 & 0.912418 & 0.001847 \\
LNER & 0.981095 & 0.805237 & 0.912418 & 1.000000 & 0.013995 \\
LO_GAP & 0.091439 & 0.069418 & 0.001847 & 0.013995 & 1.000000 \\
\hline
\end{tabular}

\subsubsection{Pairwise Granger Causality}

The pairwise granger causality shows the long run causation between two variables at a time, providing a basis to determine whether, in the long run, a change in one variable can cause a change in another. The test result revealed four unidirectional causal relationships, with the nominal exchange rate (LNER) seen to have a highly significant causality on both consumer prices (LCPI) and government expenditure (LG_EXP). Similarly, both consumer prices and money supply (LM2) were proven to have a significant causal relationship with government expenditure. Furthermore, the result complements or further justifies the inference deduced from the correlation matrix.

Table 4: Pairwise Granger Causality Tests.

\begin{tabular}{|c|c|c|c|c|}
\hline Null Hypothesis & Obs & F-Statistic & Prob. & \\
\hline LG_EXP does not Granger Cause LCPI & \multirow{2}{*}{38} & 0.61273 & 0.5479 & \multirow{2}{*}{ Unidirectional } \\
\hline LCPI does not Granger Cause LG_EXP & & 7.28826 & 0.0024 & \\
\hline LM2 does not Granger Cause LCPI & \multirow{2}{*}{38} & 0.87134 & 0.4278 & \multirow{6}{*}{ Unidirectional } \\
\hline LCPI does not Granger Cause LM2 & & 1.83459 & 0.1756 & \\
\hline LNER does not Granger Cause LCPI & \multirow{2}{*}{38} & 5.80822 & 0.0069 & \\
\hline LCPI does not Granger Cause LNER & & 0.54730 & 0.5837 & \\
\hline LO_GAP does not Granger Cause LCPI & \multirow{2}{*}{38} & 0.91570 & 0.4102 & \\
\hline LCPI does not Granger Cause LO_GAP & & 0.32109 & 0.7276 & \\
\hline LM2 does not Granger Cause LG_EXP & \multirow{2}{*}{38} & 10.1512 & 0.0004 & \multirow{2}{*}{ Unidirectional } \\
\hline LG_EXP does not Granger Cause LM2 & & 0.40829 & 0.6681 & \\
\hline LNER does not Granger Cause LG_EXP & \multirow{2}{*}{38} & 4.98777 & 0.0128 & \multirow{2}{*}{ Unidirectional } \\
\hline LG_EXP does not Granger Cause LNER & & 0.39464 & 0.6771 & \\
\hline
\end{tabular}


LO_GAP does not Granger Cause LG_EXP

LG_EXP does not Granger Cause LO_GAP

LNER does not Granger Cause LM2

LM2 does not Granger Cause LNER

LO_GAP does not Granger Cause LM2

LM2 does not Granger Cause LO_GAP

LO_GAP does not Granger Cause LNER

LNER does not Granger Cause LO_GAP

$\begin{array}{lll}38 & 0.00324 & 0.9968 \\ & 0.07160 & 0.9311 \\ 38 & 2.70933 & 0.0814 \\ & 0.69687 & 0.5053 \\ 38 & 0.03133 & 0.9692 \\ & 0.04520 & 0.9559 \\ 38 & 0.83402 & 0.4432 \\ & 0.32146 & 0.7273\end{array}$

\subsubsection{VAR Order Lag Selection}

The Akaike Information Criterion (AIC) was used as a basis for selecting the lag length. The least value for the AIC was recorded at lag 1; implying that lag 1 should be used in selecting the lag length structure for the variables to include in the VAR model. The results are presented in Table 5 below.

Table 5: VAR Lag Length Selection Criteria

\begin{tabular}{ccccccc}
\hline \multicolumn{7}{c}{ Endogenous variables: LO_GAP LNER LM2 LG_EXP LCPI } \\
\hline Lag & LogL & LR & FPE & AIC & SC & HQ \\
\hline 0 & 23.68062 & NA & $2.51 \mathrm{e}-07$ & -1.009763 & -0.792071 & -0.933016 \\
1 & 240.4093 & $363.1670^{*}$ & $8.03 \mathrm{e}-12^{*}$ & $-11.37348^{*}$ & $-10.06733^{*}$ & $-10.91300^{*}$ \\
2 & 251.5101 & 15.60108 & $1.84 \mathrm{e}-11$ & -10.62217 & -8.227559 & -9.777955 \\
3 & 269.0589 & 19.92034 & $3.40 \mathrm{e}-11$ & -10.21940 & -6.736337 & -8.991459 \\
\hline
\end{tabular}

* indicates lag order selected by the criterion; LR: sequential modified LR test statistic (each test at $5 \%$ level); FPE: Final prediction error; AIC: Akaike information criterion; SC: Schwarz information criterion; HQ: Hannan-Quinn information criterion

Results of the VAR estimation is provided in Appendix 1, with relevant stability test outcome to show the efficiency of the relationship between variables.

\subsubsection{Impulse Response Functions (IRF)}

The IRF detects the influence of a one standard deviation innovation to the orthogonalized innovation in the current and future value of each endogenous variable between and among them. In the autoregressive form of the model, each innovation, $v m t$, can be identified with a specific variable in $\mathbf{y} t$, say $y m t$ (Brooks, 2008). The results of the IRF are captured in figure 1 below. 
Figure 3. Impulse Response Functions

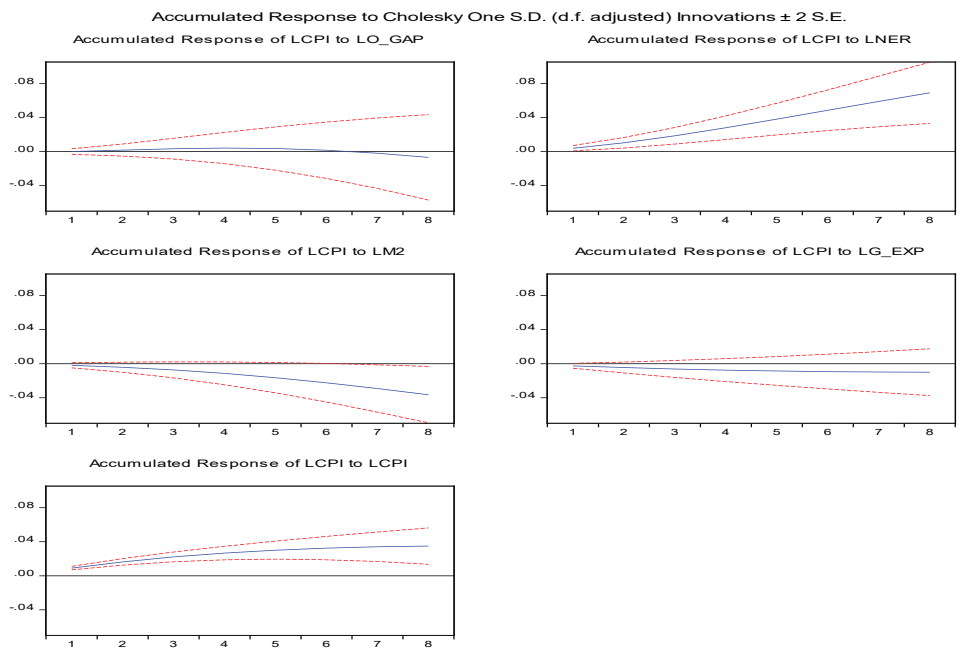

Figure 3 above captures the estimated impulse responses of the VAR model, with ordering: LO_GAP $\rightarrow$ LNER $\rightarrow$ LM2 $\rightarrow$ LG_EXP $\rightarrow$ LCPI, which was informed by the granger causality test. The rationale for utilising the VAR is to gain insights on how inflation responds to one standard deviation shocks or innovations stemming from monetary policy, supply-side and other factors; this is underpinned by the motive to exploring the possibility of the BSL adopting a policy shift into fully-fledged or lite IT regime in Sierra Leone. A period of 8 quarters in the future was utilised in analysing impulse responses as a way of determining whether the currently utilised hybrid monetary targeting regime is adequate for the primary objective of maintaining price stability in Sierra Leone, which will help in its decision making on migrating into an IT style framework.

In view of the above prelude, a one-time innovation in government expenditure (LG EXP - treated as a proxy for fiscal concern) and Output Gap (LO_GAP) revealed the negligible or insignificant impact on inflation (LCPI), both in the short run and the long run. A one-time shock to the money supply (LM2) on inflation was negative and insignificant in the first four periods, which picked up in the more distant periods $(5,6,7$, and 8 quarters) and was weakly significant afterward.

In addition, a shock emanating from Exchange Rate (LNER) came with a one-period lag and was significant and persistent going forward. This is an indication that depreciation or an appreciation in the exchange rate can potentially send shockwaves to inflation in Sierra Leone - implying that exchange rate is quite influential on price developments in the country, through the cost of imported goods, which translates into a spiraling effect on inflation in the domestic 
economy (Jackson, Tamuke and Jabbie, 2019). Given the weak state of real sector operations in the domestic economy, this is likely to pose a serious threat as expectations on the need to consume essential imports (notably inelastic goods) will continue to reign in the minds of economic agents. This is corroborated by the response of CPI to its shock, which was immediate, persistent, and significant - signaling the presence of inflation inertia.

\subsubsection{Variance Decomposition (VD)}

The VD assesses the comparative significance of innovation in describing variations in the behavior of a variable. It gives the percentage of the variance in the dependent variable resulting from their 'own' shocks, and against shocks emanating from other variables (Brooks, 2008). The figure below presents the results of the VD estimates.

Figure 4. Variance decomposition of LCPI using cholesky (d.f. adjusted) factors

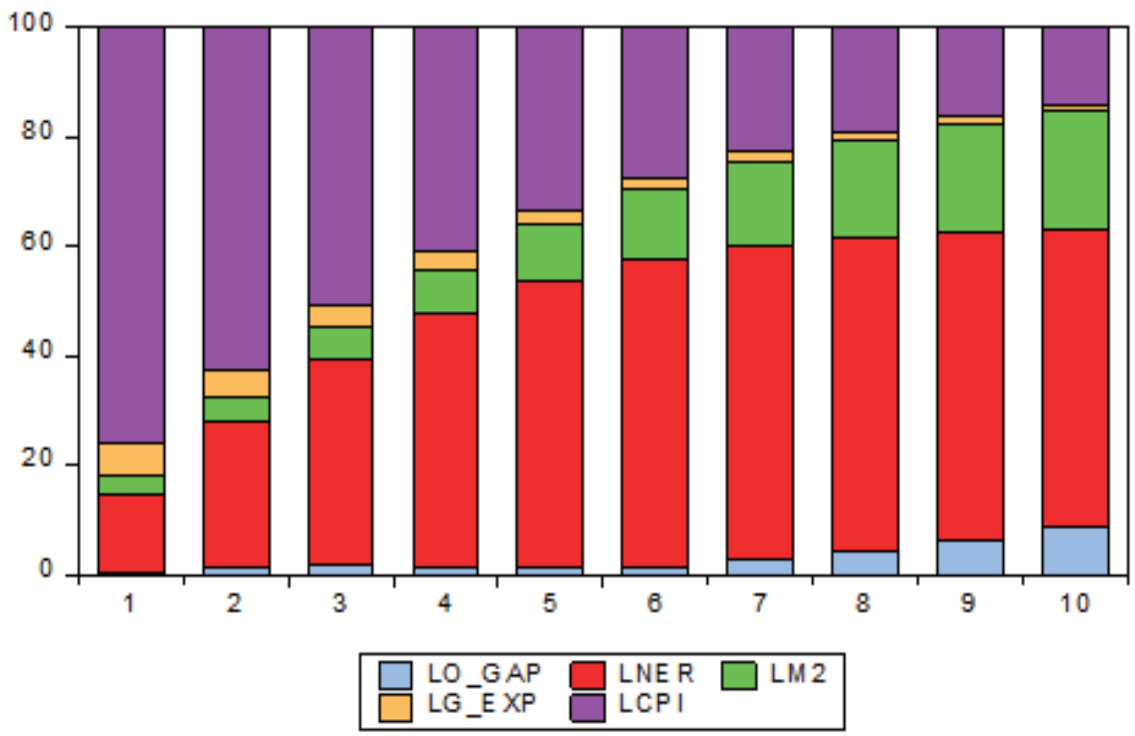

Source: EVIEWS Output

Figure 4 above shows estimates of the variance decomposition of inflation. The forecast error variance in inflation (LCPI) is strongly endogenous to its shock, indicating that inflation has a strong influence on itself, reinforcing the reasoning from the impulse response function and the subject of adaptive expectations, which drives inflation inertia - indicating that past inflation is a good predictor of its current and future trends. Exchange Rate (LNER) also has a 
strong endogenous impact on inflation both in the short run and long run, thus making it a robust predictor of price movements - underlining the pass-through of exchange rate changes to prices in Sierra Leone, which is supported by the weak nature of real sector operations in the country. Money supply (LM2) has a negligible impact on inflation in the short run but picked up in the long run as reflected in the chart. However, the output gap (LO_GAP) and government expenditure (LG_EXP) were strongly exogenous in explaining variations in prices, implying negligible influence on prices both in the short run and long run. The results from the variance decomposition complement the inference from the impulse response functions.

\subsubsection{Historical Decomposition}

The historical decomposition is an innovation-accounting technique that was suggested by Burbridge and Harrison (1985). The underlying idea of this technique involves the transformation of forecast errors into structural residuals, thus permitting the quantification of the relative significance of certain shocks to each variable (Burbridge and Harrision, 1985), which in this study, is the core variable, inflation. Given that a potential shift from a monetary aggregate targeting to inflation targeting is structural in nature, it is imperative to decompose the observed residuals into structural innovations, so that an examination could be conducted on how variations in inflation respond to structural shocks in the other variables. This is reflected in the figure below.

Figure 5. Historical decomposition of LCPI using cholesky (d.f. adjusted) weights

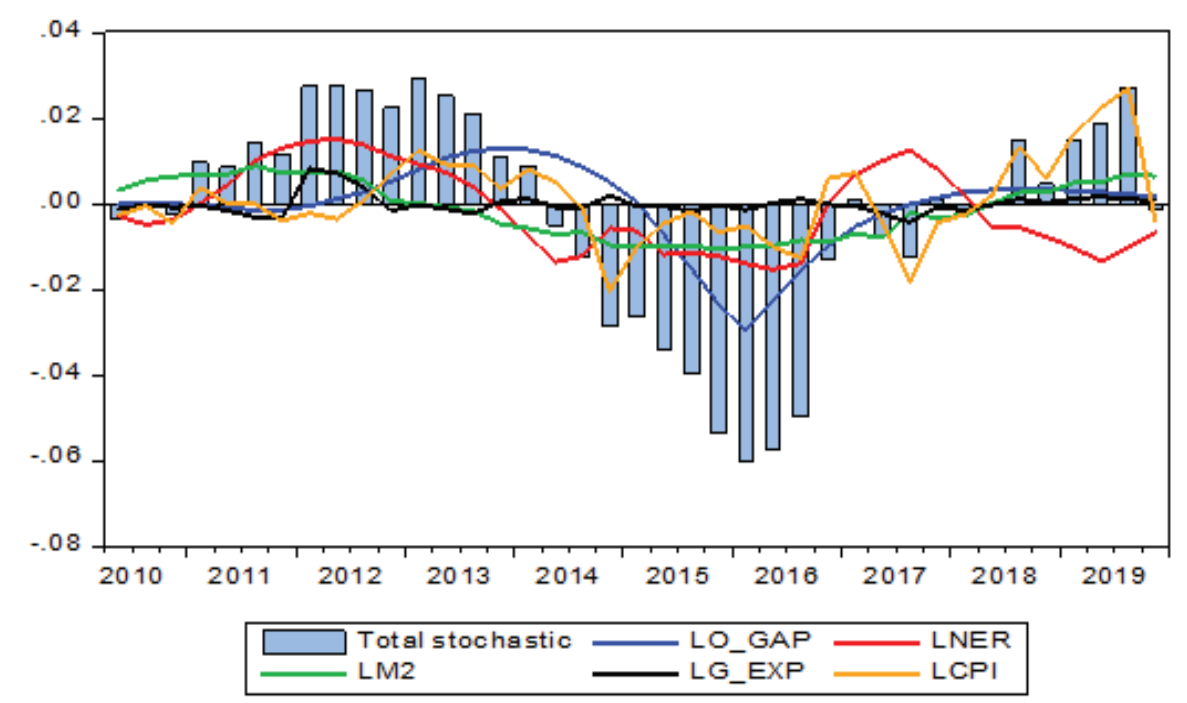

Source: EVIEWS Output 
As reflected in Figure 5 above, with the exception of government expenditure and to some extent money supply, structural shocks from inflation itself, exchange rate and the output gap to a greater extent explain the oscillation in inflation, as depicted by the bars. The inference from this chart reinforces our deduction from both the impulse response and the variance decomposition analysis about the significance of the exchange rate and inflation itself in explaining price movements in Sierra Leone. One surprise is the significance of the output gap, which as seen in the impulse response and variance decomposition, was insignificant. A logical explanation relates to the fact that the output gap is an unobserved variable derived from a structural anomaly resulting from overutilization or underutilization of productive resources, and given that the historical decomposition converts forecast errors into structural shocks, gives credence to the structural impact a gap in output will have on price movements in Sierra Leone.

\section{Empirical Discussion}

The crux of this study was to explore the possibility of adopting an IT regime in Sierra Leone. For the most part, authorities at the Bank of Sierra Leone have utilised monetary aggregate targeting an approach to control inflation, but have faced serious challenges in their attempt to bring inflation down to a desirable single-digit level (Jackson, 2020b; Jackson, Sillah and Tamuke, 2018; Tamuke, Jackson and Sillah, 2018). Problems emanating in the direction of securing a single-digit inflation target in Sierra Leone have spurred up the researchers' interest in this paper, which ultimately has given rise to the utilization of a suitable methodology to thoroughly explore the highlighted research question. For this study, the VAR model was utilised, with its justification already explained to examine the dynamic relationship between inflation and the Bank's intermediate target - variables like CPI, broad money, Output_Gap, Government Expenditure, and Exchange Rate have been used to capture myriad of dynamics, notably monetary reaction, expenditure, and supplyside factor, proxied by the exchange rate.

The outcome from the VAR estimation explains the relationship between inflation and its lag value, Exchange Rate, Output Gap, Broad Money (M2), and Government Expenditure. In utilising the VAR framework, with a focus on the endogenous dynamic relationships, aided by the impulse response functions, variance decomposition, and historical decomposition, it was deduced that the rate of inflation is strongly influenced by its past values. This is also confirmed by the VAR estimation results as shown in Appendix 1, which showed that, with all things being equal, past inflation increases current inflation by approximately 81.4 percent. The exchange rate was also proven to be a strong predictor of inflation by the analytical tools utilised, and this was corroborated by the estimate of the VAR model, which showed that ceteris paribus, exchange rate movements lead to 
approximately 13.2 percent increase in inflation (Appendix 1). Therefore, we can conclude that the Exchange rate does influence the inflation rate in Sierra Leone. The Output gap was seen to be insignificant, except for the case of the historical decomposition, which pinpointed that the structural shocks from the output gap explain price variations. Money supply and government expenditure were mostly insignificant.

Results from the empirical investigation have informed policy direction, as to whether IT implementation by the central bank is necessary or not in terms of effecting tighter economic measures for the Sierra Leone economy. IT framework as a concept has been embraced by several emerging markets and developing economies over the years, given its growing approval as a robust and effective monetary policy framework (Aliyu and Englama, 2009). However, the IT monetary policy framework is a function or a composite of several distinct requirements, which ranges from central bank independence, a well-defined inflation target, central bank transparency, and accountability as well as smooth functioning financial markets (Aliyu and Englama, 2009).

Most of the highlighted prerequisites are lacking in Sierra Leone, and that coupled with the presence of several structural bottlenecks, there is sufficient evidence to prove that IT framework is not a worthwhile venture for adoption in the economy (Jackson and Jabbie, 2019; Bangura et al, 2012). There is a possibility for the IT framework to be successfully implemented in the long run by the Bank given the strides management is taking to effectively utilise the revised BSL Act 2019 in affirming its autonomy, with the possibility of ensuring preparedness for its implementation in the medium to long term period. This is of course contingent on determining whether IT framework is a viable option compared to monetary aggregate targeting currently in use by the BSL.

On this note, though VAR is well-founded on macroeconomic tenets, with its questionable theoretical base, it, however, provides a strong platform to empirically assess the dynamics between Inflation and among variables (Jackson, Tamuke, and Jabbie, 2019; Saleem, 2010). The results from the impulse response, variance decomposition, and historical decomposition showed weak dynamics between inflation and money supply in the short-run, while a strong influence was proven to be present between inflation and a shock to itself, and as well as the heavy influence of exchange rate movements and to some extent the output gap (based on the historical decomposition). This lays the basis to empirically suggest that the IT framework is not a viable option for implementation in the short and medium-term. More so, given the weak state of real sector operations in the country (as indicated in the output gap), with supply-side driven indicators like Exchange Rate dominating the state of economic activities in the country, the possibility of IT implementation in addressing price stability is far-fetched. 


\section{Robustness Check and Tests Outcomes}

The VAR model at lag 1 was tested for robustness (using the five percent level of significance as a baseline) and stability (see VAR estimation output in Appendix 1). It was inferred from the result that the model is stable as all AR roots were within the unit circle. In terms of robustness, the model passed the serial correlation and Heteroskedasticity tests but failed the normality test. However, according to the Central Limit Theorem: given random and independent samples of $N$ observations each, the distribution of sample means approaches normality as the size of $N$ increases, regardless of the shape of the population distribution (Mordkoff, 2016). Therefore, despite failing the normality test, given that $\mathrm{N}>30$ in this study, it is assumed that the sample is normal. Details of the robustness and stability tests are in Appendices 2 and 1 respectively.

Moreover, to further solidify the robustness of the VAR model utilised with the initially identified endogenous variables, the researchers replaced broad money supply (intermediate target of the BSL) with reserve money (which happens to be the operating target). This was done to ascertain whether the model properties would change, notably improve, or deteriorate, with the inclusion of the new variable. In this regard, the results indicated little or an insignificant deviation from the initial results, thus confirming that the initial model was robust. The results of the new model estimation are in Appendix 2.

\section{Conclusion and Policy Recommendations}

This paper explored the possibility of a fully-fledged or lite IT framework being adopted in Sierra Leone by the Bank of Sierra Leone through the use of historical data spanning from 2010Q2 to 2019Q4. We commenced by studying the statistical features of the variables, establishing correlations, and ascertaining causal relationships between the chosen variables, for which there was evidence of four uni-directional causal relationships between many of the variables as shown in Table 4. Based on the first objective of the study, which utilizes VAR estimation (and supported relevant innovation shocks, notably Impulse Responses, Variance Decomposition, and Historical Decomposition), we can conclude that inflation in Sierra Leone is more of own-self and exchange rate driven, with some structural impact from the output gap. Given these developments, inflation will continue to pose a serious threat to the country's macroeconomic stability as economic agents' appetite for imported goods cannot be easily substituted, given the weak state of real sector activities in the country (also reflected in the output gap trend) - an indication to show that IT, particularly fully-fledged is not an option for the country in the short to medium term, given the fragility of the economy to cope in a time of (external) shocks. 
The current approach of the BSL to monitor price stability through instruments like forecast model is considered very useful to plan and support policy formulation, particularly in sectors of the economy that is proving very difficult in support of the consideration for IT adoption (see Jackson, Tamuke and Jabbie, 2019). The economy is highly susceptible to external shocks, owing to the weak state of real sector operation, which also weakens the competitive state of the country's currency towards continued depreciation and high costpush in prices of goods and services, even in the medium to long term periods (Jackson, 2020; Jackson, Tamuke and Jabbie, 2019; Bangura, Denison-George and Caulker, 2013).

With the current dynamics in the domestic economy, it is advisable for authorities at the BSL to continue efforts of reviewing the objective focus as reflected in the revised BSL Act 2019. It is very indicative (as highlighted in the Impulse Response and Variance Decomposition shocks) that the country would need to strengthen its financial sector, amid a much-needed boost in key areas connected with real sector operations and export promotion to supporting a well-informed decision on its drive to adopt a fully-fledged or lite IT framework.

The revised BSL Act 2019 has given way for a second objective, which is financial stability, and it is believed that this will help address on-going concerns in the banking sector. This means that the formation of the Financial Policy Committee (FPC) is a welcoming addition in complementing that of the already established MPC to scrutinise the wider macroeconomic concerns in the country that are considered risky to adopting IT framework in the country. While these two committees need to work cooperatively, there is also an onus on the need for government to boost real sector operations, which can also be championed through targeted financing in agricultural productivity for example, from competitive rates in commercial banks. Currently, there is a huge task on the country in meeting demand expectations for essential goods and services in the domestic economy - a shortfall in domestic production will always fuel high demand for foreign currency to pay for imported items and the pass-through effect of this will be felt for quite a long period. With all of these settings in place, there is a high chance for the BSL to adopt an aggressive stance in utilising available monetary instruments to venture into an IT-lite regime as currently mirrored through its announced long-term target for inflation in the country.

In the current climate, Sierra Leone is not operating on a normal market-based system, where the forces of demand and supply are seen as the driving forces to economic sustainability and prosperity (Jackson and Jabbie, 2020). Therefore, in pursuit of the move to consider IT framework, which comes with countless limitations (Saleem, 2010), the BSL will need to be very cautious in utilising available instruments, while also adopting some form of moral suasion in cajoling economic agents and government alike on collaborative partnership in ensuring the target of achieving single-digit inflation is made possible. Such 
operation will require the government's effort to diversify investment in real sector activities, as opposed to increasing spending on non-essential services associated with travelling and the already expanded diplomatic mission overseas, which is proving to be more of a burden than value-added to government finances. At the same time, the BSL should also be intrusive in ensuring its announced policy rates are effectively utilized by commercial banks to induce competitive rates for investors in areas connected with agriculture and the service industry to boost essential economic activities.

The long-gone financial crisis that surfaced in the country's fragile governance needs transparent policy revision - thankfully, the revised BSL and Banking Acts of 2019 have touched on this, and also, the independent status of the bank seems to be taking positive trajectory through the action of management intervention in the exchange rate market, particularly in subduing illegal street trading activities and the need for public announcements on critical matters. The increasing intensity of historical financial crises the country witnessed around 2015-2018 demand transparent policies through regular revision of the BSL and Banking Acts (Tahir, 2004), and also impending commitments to informing the public about the bank's intention to address issues of going concerns.

Based on the above discourses, which is highly supported by our use of VAR model, we have concluded that IT framework (both the fully-fledged and lite) is not an option for the Sierra Leone economy given the present state of structural bottlenecks - there is a need for the country and more so the BSL to support government approach towards operating on a transparent and market-led system, which requires less interference on the central bank's action to utilise relevant policy instruments to drive down inflation - this in most cases will come at the huge cost given the weak state of real sector operations, which will also serve as a way for key stakeholders in the public service to effectively utilize policies aimed at boosting productive activities in addressing domestic demand for essential goods and services consumed (Jabbie and Jackson, 2019; Jackson, 2020b).

On a final note, it is highly recommended that commitment is made to support the continuous revision of existing Acts (BSL, Banking, and other relevant statutes) in a bid to put the BSL in the spotlight of achieving low inflation in Sierra Leone. Equally, there is a need for the BSL to continue its current operation of developing a suite of models (notably Forecasting and Policy Analysis Systems [FPAS], in addition to currently utilised short-term models like ARIMA, VAR, VECM, and ARDL) to continue its drive to monitor medium to long term quarterly inflation outlook, which is very critical in the pursuit of collaboration with government and other stakeholders on measures it intends to take in achieving its desired long-term objective towards single-digit inflation. 
Acknowledgement(s): At this juncture, the authors wish to express appreciation to named individuals who in diverse ways have helped towards the accomplishment of this research endeavour - notable highlights include Mr. Morlai Bangura, Director of Research at the Bank of Sierra Leone (BSL), whose effort has been immense in providing critical comments on the work. We also extend our sincere appreciation to Mr. Rashid Koroma and his team in the BoP section, BSL for availing essential data in completing the empirical task. Equally and on a different pursued effort is Ms. Margaret Decker, the Librarian at the BSL whose kindness could not be forgotten throughout the process of extracting relevant information pertaining to the historical development of Acts of the BSL and other statutes since its inception and date.

Peer-review: Externally peer-reviewed.

Conflict of Interest: The authors have no conflict of interest to declare.

Grant Support: The authors declared that this study has received no financial support.

\section{References}

Aliyu, S.U.R., \& Englama, A. (2009). Is Nigeria ready for inflation targeting? MPRA. Retrieved from https://mpra. ub.uni-muenchen.de/14870/.

Akerlof, G.A., Perry, G.L., \& Dickens, W.T. (1996). The macroeconomics of low inflation. Brookings Papers on Economic Activity, 1(1996), 1-59.

Angeriz, A., \& Arestis, P. (2007). Assessing inflation targeting through intervention analysis. Oxford Economic Papers, 60(2), 293-317.

Araújo E. L., de Araújo E. C., da Fonseca M. R., \& da Silva P. P. (2020). Inflation targeting regime and the global financial cycle: An assessment for the Brazilian economy. PSL Quarterly Review, 73 (292), 27-49. DOI: 10.13133/2037-3643_73.292_2.

Ball, L., \& Sheridan, N. (2005), Does inflation targeting matter? In Bernanke, Ben S., and Michael Woodford (eds.), The Inflation-Targeting Debate, The University of Chicago Press, 249-276.

Ball, L. (2010). The performance of alternative monetary regimes, Handbook of Monetary Economics, 3(2010), 1303-1343.

Bangura, M., Caulker, E. \& Pessima, S. (2012). Exchange rate pass-through to inflation in Sierra Leone: A structural vector autoregressive approach. Journal of Monetary and Economic Integration, 12(1), 93-123.

Bangura, M., Denison-George, C., \& Caulker, R. (2013). The impact of exchange rate dynamics on the trade balance in Sierra Leone: An ARDL Cointegration Approach. Journal of Monetary and Economic Integration, 13(1), 64-88.

Bernanke, B. S. \& F. S. Mishkin. (1997). “Inflation targeting: a new framework for monetary policy?” Journal of Economic Perspectives, 11(2), 97-116.

Bernanke, Ben S., Thomas Laubach, Frederic S. Mishkin, \& Adam S. Posen (1999). Inflation targeting: lessons from the international experience. USA: Princeton University Press.

Bleaney, M., Morozumi, A. \& Mumuni, Z. (2020), Inflation targeting and monetary policy in Ghana, Journal of African Economies, 29(2), 121-145, DOI: 10.1093/jae/ejz021.

Brooks, C. (2008). Introductory econometrics for finance ( $6^{\text {th }}$ ed.). Cambridge: Cambridge University Press.

Brownbridge, M., \& Kasekende, L. (2018). Inflation targeting in Uganda: What lessons can we learn from five years of experience? In, Andrew Berg and Rafael Portillo (ed.). Monetary Policy in Sub-Saharan Africa. Oxford Scholarship Online. Retrieve from doi: 10.1093/oso/9780198785811.003.0002.

BSL. (2019a). The Bank of Sierra Leone Act, 2019. Retrieve from http://www.bsl.gov.sl/Bank\%20of\%20Sierra\%20 Leone\%20Ascent\%202019.pdf. 
BSL. (2019b). The Bank Act of 2019. Retrieve from http://www.bsl.gov.sl/The\%20\%20Banking\%20Act\%202019.pdf.

BSL. (2017). Governor's Annual Dinner Speech 2017. Retrieve from http://www.bsl.gov.sl/Gov\%20Dr\%20 Kaifala\%20Marah\%20Dinner\%20Speech\%20-\%20Feb\%202017.pdf.

BSL Act. (2011). The Bank of Sierra Leone Act, 2011. Retrieve from http://www.bsl.gov.sl/BSL_Act_2011.pdf.

Burbridge, J. \& Harrison, A. (1985). A historical decomposition of the great depression to determine the role of money. Journal of Monetary Economics, 16(1), 45-54. DOI: 10.1016/0304-3932(85)90005-4.

Carare, A., Schaechter, A., Stone, M., \& Zelmer, Z. (2002). Establishing initial conditions in support of inflation targeting. IMF Working Papers, No: WP/02/102. Retrieve from https:/www.elibrary.imf.org/doc/ IMF001/02082-9781451852622/02082-9781451852622/Other_formats/Source_PDF/02082-9781451898231. pdf?redirect=true.

Chaudhry, M.A., \& Chaudhry, M.A.S. (2005). Why the State Bank of Pakistan should not adopt inflation targeting. Retrieve from http://www.sbp.org.pk/research/conf/Session_III_Aslam_Munir.pdf.

Debelle, G., Masson, P., \& Savastano, M. (1998). Inflation Targeting as a Framework for Monetary Policy. Economic Issues No. 15. International Monetary Fund. Retrieve from https://www.imf.org/external/pubs/ft/ issues/issues $15 /$.

Fischer, S. (2000). Opening remarks by Stanley Fischer, IMF Institute's High-Level Seminar on Implementing Inflation Targets. Retrieve from http://www.imf.org/external/np/speeches/ 2000/032000.htm.

Frankel, J. (2012). "The death of inflation targeting”, Retrieve from http://www.VoxEU. Org.

Gottshalk, J., \& Moore, D. (2001). Implementing inflation targeting regimes: The case of Poland. Journal of Comparative Economics, 29(1), 24-39. Retrieve from DOI: 10.1006/jcec.2000.1699.

Heintz, J. \& Ndikumana, L. (2011). Is there a case for formal inflation targeting in Sub-Saharan Africa? Journal of African Economies, 20(2), ii67-ii103. Doi: 10.1093/jae/ejq027.

Hammond, G. (2012). State of the art of inflation targeting - 2012. Handbook, No. 29. Centre for Central Banking Studies, Bank of England. Retrieve from https://web.archive.org/web/20170811125823/http://www. bankofengland.co.uk/education/Documents/ccbs/handbooks/pdf/ccbshb29.pdf.

Jackson, E.A. (2020a). Emerging innovative thoughts on globalization amidst the contagion of COVID-19. In: Leal Filho W., Azul A., Brandli L., Özuyar P., Ozuyar, P.G. (ed.) Industry, Innovation, and Infrastructure. Encyclopedia of the UN Sustainable Development Goals. Springer, Cham. DOI: 10.1007/978-3-319-71059-4_131-1.

Jackson, E.A. (2020b). Understanding SLL/US\$ exchange rate dynamics in Sierra Leone using the Box-Jenkins ARIMA approach. MPRA Paper No. 97965.

Jackson, E.A. (2020c). Importance of the public service in achieving the UN SDGs. In Walter L. Filho, et al. (ed.). Decent Work and Economic Growth: Encyclopedia of Sustainable Development Goal, Springer Nature Publisher. DOI: 10.1007/978-3-319-71058-7_20-2

Jackson, E.A. (2018): comparison between static and dynamic forecast in autoregressive integrated moving average for seasonally adjusted headline consumer price index. revista economicã, 70(1), 53-65.

Jackson, E.A., \& Jabbie, M. (2020). Twin deficits hypothesis as an indication of government failure in Sierra Leone: an empirical investigation (1980 - 2018), Journal of Economic Policy Researches, 7(1), 43-68. DOI: $10.266 \mathrm{R} 658440$.

Jackson, E.A., \& Jabbie, M. (2019). Understanding market failure in the developing country. Context (Online First). In, Walter L. Filho (eds), Decent Work and Economic Growth: Encyclopedia of Sustainable Development Goals, Springer Nature Publisher. DOI: 10.1007/978-3-319-71058-7_44-1.

Jackson, E.A. \& Tamuke, E. (2018). Probability forecast using fan chart analysis: A case of the Sierra Leone economy. Journal of Advanced Studies in Finance, 9(1), 34-44. DOI: 10.14505//jasf.v9.1(17).04. 
Jackson, E.A., Jabbie, M., \& Tamuke, E. (2019). Dynamic effect of inflation shocks in Sierra Leone: An empirical analysis. Journal of Advanced Studies in Finance, 10(2), 73-91. DOI: 10.14505/jasf.v10.2(20).01.

Jackson, E.A., Sillah, A., \& Tamuke, E. (2018). Modelling monthly headline consumer price index (HCPI) through Seasonal Box-Jenkins methodology. International Journal of Sciences, 7(1), 51-56. DOI: 10.18483/ijSci.1507.

Jahan, S. (Online). Inflation Targeting: Holding the Line. Retrieve from https://www.imf.org/external/pubs/ft/ fandd/basics/pdf/jahpan-inflation-targeting.pdf.

Kallon, K.M. (1994). An econometric analysis of inflation in Sierra Leone. Journal of African Economies, 3(2), 199-230. DOI: 10.1093/oxfordjournals.jae.a036804.

Kelikume, I., \& Evans, O. (2015) Inflation targeting as a possible monetary framework for Nigeria. The International Journal of Business and Finance Research, 9(5), 71-81. Retrieve from https://ssrn.com/ abstract $=2664755$.

Lavally, M. \& Nyambe, J.M. (2019). The effectiveness of transmission mechanisms of monetary policy in Sierra Leone. Journal of Economics, Management, and Trade, 23(2), 1-13. Doi: 10.9734/JEMT/2019/v23i230128.

Mansaray M., \& Swaray, S. (2012). Financial liberalization, monetary policy, and money demand in Sierra Leone. Journal of Monetary and Economic Integration, 12(2), 62-90.

Mishkin, F.S. (2001). Inflation targeting. Retrieve from https://notendur.hi.is/ajonsson/kennsla2013/01ENCYC.pdf.

Mishkin, F.S. (2000). Inflation targeting in emerging market countries. NBER Working Paper 7618. Retrieve from http://www.nber.org/papers/w7618.

Mishkin, F.S., \& Posen, A.S. (1997). "Inflation targeting: lessons from four countries". Federal Reserve Bank of New York Economic Policy Review, August 1997: 9-110.

Roger, Scott (2009), Inflation targeting at 20: Achievements and challenges. IMF Working Paper WP/09/236.

Saleem, N. (2010). Adopting inflation targeting in Pakistan: An empirical analysis. The Lahore Journal of Economics, 15(2), 51-73.

Sims, C.A. (1986). Are forecasting models usable for policy analysis? Quarterly Review, Federal Reserve Bank of Minneapolis, 10(Win), 2-16.

Sims, C.A. (1980). Macroeconomics and reality. Econometrica, 48(1), 1-48. DOI: 10.2307/1912017.

Svensson, L. E. 2010. Inflation targeting. Handbook of Monetary Economics, 3, 1237-1302.

Svensson, L. E. O. (2000). Open-economy inflation targeting. Journal of International Economics, 50(1), $155-183$. DOI: $10.1016 / \mathrm{S} 0022-1996(98) 00078-6$.

Svensson, L. E. O. (1999). Price Level Targeting vs. Inflation Targeting: A Free Lunch? Journal of Money, Credit and Banking, 31, 277-95.

Tahir, P. (2004). Institutional arrangements for financial sector governance. SBP Research Bulletin, 2(1), 283-310.

Tamuke, E., Jackson, E.A., \& Sillah, A. (2018). Forecasting inflation in Sierra Leone using ARIMA and ARIMAX: A comparative evaluation. Theoretical and Practical Research in the Economic Fields, 9(1(17)), 63-74.

Taylor, J.B. (2019). Inflation targeting in high inflation emerging economies: Lessons about rules and instruments. Journal of Applied Economics, 22(1), 103-116. DOI: 10.1080/15140326.2019.1565396.

Taylor, J. B. 2007. Housing and Monetary Policy. NBER Working Paper, No. 13682.

Truman, Edwin M. (2003), inflation targeting in the world economy, Peterson Institute for International Economics.

Warburton, C.E.S., \& Jackson, E.A. (2020). Monetary policy responses to exogenous perturbations: The case of a small open economy (2007-2018). PSL Quarterly Review, 73(293), 181-201. DOI: 10.13133/20373643_73.293_5. 


\section{APPENDIX 1}

Appendix 1A: Descriptive Statistics

\begin{tabular}{lccccc}
\hline & LCPI & LG_EXP & LM2 & LNER & LO_GAP \\
\hline Mean & 5.094601 & 6.946393 & 15.26493 & 8.617546 & 2.280936 \\
Median & 5.005666 & 7.009864 & 15.34985 & 8.493336 & 2.419841 \\
Maximum & 5.639066 & 7.718329 & 15.95945 & 9.181048 & 3.396651 \\
Minimum & 4.730127 & 5.276165 & 14.30383 & 8.262174 & -1.919502 \\
Std. Dev. & 0.276277 & 0.518700 & 0.457994 & 0.291730 & 0.985076 \\
Skewness & 0.593297 & -0.819189 & -0.369959 & 0.525502 & -2.509459 \\
Kurtosis & 2.096500 & 3.912728 & 2.119788 & 1.720663 & 10.88054 \\
& & & & & 145.4875 \\
Jarque-Bera & 3.707198 & 5.862253 & 2.203754 & 4.568853 & 0.000000 \\
Probability & 0.156672 & 0.053337 & 0.332247 & 0.101832 & \\
& & & & & 31.23744 \\
Sum & 203.7840 & 277.8557 & 610.5973 & 34.7018 & 37.84458 \\
Sum Sq. Dev. & 2.976822 & 10.49293 & 8.180590 & 3.319140 & 40 \\
Observations & 40 & 40 & 40 & 40 & \\
\hline
\end{tabular}




\section{Appendix 1B: VAR Estimation Output}

\begin{tabular}{|c|c|c|c|c|c|}
\hline \multicolumn{6}{|c|}{ Vector Autoregression Estimates } \\
\hline \multicolumn{6}{|c|}{ Date: $05 / 03 / 20$ Time: $14: 03$} \\
\hline \multicolumn{6}{|c|}{ Sample (adjusted): 2010Q2 2019Q4 } \\
\hline \multicolumn{6}{|c|}{ Included observations: 39 after adjustments } \\
\hline \multicolumn{6}{|c|}{ Standard errors in ( ) \& t-statistics in [ ] } \\
\hline & LO_GAP & LNER & LM2 & LG_EXP & LCPI \\
\hline \multirow[t]{3}{*}{ LO_GAP(-1) } & 0.699938 & -0.007253 & 0.000282 & 0.023035 & 0.002670 \\
\hline & $(0.14148)$ & $(0.00493)$ & $(0.00637)$ & $(0.05603)$ & $(0.00197)$ \\
\hline & {$[4.94711]$} & {$[-1.47079]$} & {$[0.04427]$} & {$[0.41112]$} & {$[1.35525]$} \\
\hline \multirow[t]{3}{*}{$\operatorname{LNER}(-1)$} & 0.372079 & 0.952809 & -0.030888 & 0.085292 & 0.132250 \\
\hline & $(2.35690)$ & $(0.08215)$ & $(0.10613)$ & $(0.93336)$ & $(0.03282)$ \\
\hline & {$[0.15787]$} & [ 11.5990$]$ & {$[-0.29103]$} & {$[0.09138]$} & [ 4.02961] \\
\hline \multirow[t]{3}{*}{ LM2(-1) } & 1.681035 & -0.209691 & 0.605624 & -0.340341 & -0.024693 \\
\hline & $(2.46445)$ & $(0.08589)$ & $(0.11098)$ & $(0.97595)$ & $(0.03432)$ \\
\hline & {$[0.68211]$} & {$[-2.44127]$} & [ 5.45729] & {$[-0.34873]$} & {$[-0.71955]$} \\
\hline \multirow[t]{3}{*}{ LG_EXP(-1) } & -0.166957 & 0.002187 & 0.007971 & -0.032696 & 0.000426 \\
\hline & $(0.45446)$ & $(0.01584)$ & $(0.02046)$ & $(0.17997)$ & $(0.00633)$ \\
\hline & {$[-0.36737]$} & [0.13809] & {$[0.38952]$} & {$[-0.18168]$} & [ 0.06728$]$ \\
\hline \multirow[t]{3}{*}{ LCPI(-1) } & 2.355976 & -0.173801 & -0.165884 & -0.621166 & 0.814360 \\
\hline & $(3.94212)$ & $(0.13740)$ & $(0.17752)$ & $(1.56112)$ & $(0.05489)$ \\
\hline & {$[0.59764]$} & {$[-1.26496]$} & {$[-0.93448]$} & {$[-0.39790]$} & [ 14.8352] \\
\hline \multirow[t]{3}{*}{$\mathrm{C}$} & -36.60977 & 4.231864 & 6.739071 & 13.47598 & 0.140482 \\
\hline & $(45.5820)$ & (1.58869) & $(2.05258)$ & $(18.0510)$ & $(0.63473)$ \\
\hline & {$[-0.80316]$} & [2.66375] & [ 3.28321$]$ & {$[0.74655]$} & [0.22133] \\
\hline \multirow[t]{3}{*}{ @TREND } & -0.117509 & 0.013959 & 0.018458 & 0.063930 & 0.002786 \\
\hline & $(0.14563)$ & $(0.00508)$ & $(0.00656)$ & $(0.05767)$ & $(0.00203)$ \\
\hline & {$[-0.80688]$} & {$[2.75014]$} & [2.81454] & {$[1.10851]$} & [1.37386] \\
\hline R-squared & 0.533337 & 0.993295 & 0.995064 & 0.715279 & 0.998798 \\
\hline Adj. R-squared & 0.445838 & 0.992037 & 0.994139 & 0.661894 & 0.998573 \\
\hline Sum sq. resids & 17.60635 & 0.021387 & 0.035701 & 2.761115 & 0.003414 \\
\hline S.E. equation & 0.741754 & 0.025853 & 0.033402 & 0.293743 & 0.010329 \\
\hline F-statistic & 6.095329 & 790.0522 & 1075.217 & 13.39848 & 4432.278 \\
\hline Log likelihood & -39.83021 & 91.07739 & 81.08594 & -3.704022 & 126.8587 \\
\hline Akaike AIC & 2.401549 & -4.311661 & -3.799279 & 0.548924 & -6.146599 \\
\hline Schwarz SC & 2.700137 & -4.013073 & -3.500691 & 0.847512 & -5.848011 \\
\hline Mean dependent & 2.272298 & 8.626658 & 15.28958 & 6.968972 & 5.103946 \\
\hline S.D. dependent & 0.996417 & 0.289719 & 0.436288 & 0.505174 & 0.273408 \\
\hline \multicolumn{2}{|c|}{ Determinant resid covariance (dof adj.) } & $2.46 \mathrm{E}-12$ & & & \\
\hline \multicolumn{2}{|c|}{ Determinant resid covariance } & $9.16 \mathrm{E}-13$ & & & \\
\hline \multicolumn{2}{|l|}{ Log likelihood } & 263.8210 & & & \\
\hline \multicolumn{2}{|c|}{ Akaike information criterion } & -11.73441 & & & \\
\hline \multicolumn{2}{|l|}{ Schwarz criterion } & -10.24147 & & & \\
\hline \multicolumn{2}{|c|}{ Number of coefficients } & 35 & & & \\
\hline
\end{tabular}




\section{Appendix 1C: VAR Stability}

Roots of Characteristic Polynomial

Endogenous variables: LO_GAP LNER LM2

LG_EXP LCPI

Exogenous variables: C @TREND

Lag specification: 11

Date: 05/03/20 Time: 14:08

\begin{tabular}{cl}
\hline Root & Modulus \\
\hline $0.893107-0.104433 \mathrm{i}$ & 0.899192 \\
$0.893107+0.104433 \mathrm{i}$ & 0.899192 \\
0.714044 & 0.714044 \\
0.561281 & 0.561281 \\
-0.021504 & 0.021504 \\
\hline
\end{tabular}

No root lies outside the unit circle.

VAR satisfies the stability condition.

\section{Appendix 1D: VAR Serial Correlation}

VAR Residual Serial Correlation LM Tests

Date: 05/03/20 Time: 14:06

Sample: 2010Q1 2019Q4

Included observations: 39

Null hypothesis: No serial correlation at lag $\mathrm{h}$

\begin{tabular}{lcccccc}
\hline Lag & LRE* stat & df & Prob. & Rao F-stat & df & Prob. \\
\hline 1 & 15.88430 & 25 & 0.9182 & 0.608957 & $(25,86.9)$ & 0.9202 \\
2 & 14.74832 & 25 & 0.9471 & 0.562070 & $(25,86.9)$ & 0.9484 \\
\hline Null hypothesis: No serial correlation at lags 1 to h \\
\hline 1 & LRE* stat & df & Prob. & Rao F-stat & df & Prob. \\
\hline & 15.88430 & 25 & 0.9182 & 0.608957 & $(25,86.9)$ & 0.9202 \\
\hline
\end{tabular}

*Edgeworth expansion corrected likelihood ratio statistic. 


\section{Appendix 1E: VAR Heteroscedasticity}

VAR Residual Heteroskedasticity Tests (Levels and Squares)

Date: 05/03/20 Time: 14:08

Sample: 2010Q1 2019Q4

Included observations: 39

\begin{tabular}{|c|c|c|c|c|c|}
\hline \multicolumn{6}{|c|}{ Joint test: } \\
\hline \multicolumn{2}{|c|}{ Chi-sq } & \multicolumn{2}{|c|}{ df } & \multicolumn{2}{|c|}{ Prob. } \\
\hline \multicolumn{2}{|c|}{209.7671} & \multicolumn{2}{|c|}{180} & \multicolumn{2}{|c|}{0.0637} \\
\hline \multicolumn{6}{|c|}{ Individual components: } \\
\hline Dependent & R-squared & $F(12,26)$ & Prob. & Chi-sq(12) & Prob. \\
\hline res1*res1 & 0.965626 & 60.86587 & 0.0000 & 37.65942 & 0.0002 \\
\hline res $2 *$ res 2 & 0.296839 & 0.914659 & 0.5462 & 11.57674 & 0.4802 \\
\hline res $3 *$ res 3 & 0.319373 & 1.016674 & 0.4625 & 12.45556 & 0.4098 \\
\hline res $4 *$ res 4 & 0.210025 & 0.576038 & 0.8413 & 8.190993 & 0.7700 \\
\hline $\operatorname{res} 5 * \operatorname{res} 5$ & 0.326033 & 1.048131 & 0.4383 & 12.71530 & 0.3901 \\
\hline res $2 *$ res 1 & 0.516134 & 2.311156 & 0.0359 & 20.12922 & 0.0647 \\
\hline res3*res1 & 0.628579 & 3.666782 & 0.0027 & 24.51457 & 0.0173 \\
\hline res $3 *$ res 2 & 0.303869 & 0.945775 & 0.5199 & 11.85089 & 0.4577 \\
\hline res4*res 1 & 0.778630 & 7.620852 & 0.0000 & 30.36656 & 0.0025 \\
\hline res $4 *$ res 2 & 0.370248 & 1.273841 & 0.2907 & 14.43967 & 0.2735 \\
\hline res $4 *$ res 3 & 0.241935 & 0.691489 & 0.7448 & 9.435476 & 0.6654 \\
\hline res5*res1 & 0.073998 & 0.173140 & 0.9986 & 2.885906 & 0.9963 \\
\hline $\operatorname{res} 5 *$ res 2 & 0.194229 & 0.522268 & 0.8808 & 7.574918 & 0.8174 \\
\hline res $5 *$ res 3 & 0.267369 & 0.790712 & 0.6558 & 10.42740 & 0.5785 \\
\hline res5*res 4 & 0.237484 & 0.674805 & 0.7594 & 9.261889 & 0.6804 \\
\hline
\end{tabular}




\section{Appendix 1F: VAR Normality}

VAR Residual Normality Tests

Orthogonalization: Cholesky (Lutkepohl)

Null Hypothesis: Residuals are multivariate normal

Date: 05/03/20 Time: 14:09

Sample: 2010Q1 2019Q4

Included observations: 39

\begin{tabular}{lcccc}
\hline Component & Skewness & Chi-sq & df & Prob.* \\
\hline 1 & 0.256258 & 0.426844 & 1 & 0.5135 \\
2 & 1.184311 & 9.116855 & 1 & 0.0025 \\
3 & -0.369841 & 0.889085 & 1 & 0.3457 \\
4 & -2.297374 & 34.30653 & 1 & 0.0000 \\
5 & -0.895978 & 5.218045 & 1 & 0.0224 \\
\hline Joint & & 49.95736 & 5 & 0.0000 \\
\hline Component & Kurtosis & Chi-sq & df & Prob. \\
\hline 1 & 9.531693 & 69.32740 & 1 & 0.0000 \\
2 & 5.259555 & 8.296580 & 1 & 0.0040 \\
3 & 3.720985 & 0.844705 & 1 & 0.3581 \\
4 & 12.69060 & 152.6001 & 1 & 0.0000 \\
5 & 4.435178 & 3.347071 & 1 & 0.0673 \\
\hline Joint & & 234.4159 & 5 & 0.0000 \\
\hline Component & Jarque-Bera & df & Prob. & \\
\hline 1 & 69.75424 & 2 & 0.0000 & \\
2 & 17.41344 & 2 & 0.0002 & \\
3 & 1.733790 & 2 & 0.4203 & \\
4 & 186.9066 & 2 & 0.0000 & \\
5 & 8.565116 & 2 & 0.0138 & \\
\hline Joint & 284.3732 & 10 & 0.0000 & \\
\hline
\end{tabular}

*Approximate p-values do not account for coefficient Estimation 


\section{APPENDIX 2}

\section{APPENDIX 2: Robustness Check Results}

\section{Appendix 2A: Vector Autoregression Estimates}

\begin{tabular}{|c|c|c|c|c|c|}
\hline \multicolumn{6}{|c|}{$\begin{array}{l}\text { Date: 05/03/20 Time: } 17: 45 \\
\text { Sample (adjusted): 2010Q2 2019Q4 } \\
\text { Included observations: } 39 \text { after adjustments } \\
\text { Standard errors in ( ) \& t-statistics in [ ] }\end{array}$} \\
\hline & LO_GAP & LNER & LRM & LG_EXP & LCPI \\
\hline \multirow[t]{3}{*}{ LO_GAP(-1) } & 0.704625 & -0.007295 & 0.010319 & 0.022944 & 0.002651 \\
\hline & $(0.14208)$ & $(0.00476)$ & $(0.01349)$ & $(0.05599)$ & $(0.00198)$ \\
\hline & [ 4.95948] & {$[-1.53301]$} & {$[0.76473]$} & {$[0.40980]$} & [ 1.34137$]$ \\
\hline \multirow[t]{3}{*}{ LNER(-1) } & 0.408950 & 0.980947 & 0.118206 & 0.129645 & 0.134705 \\
\hline & $(2.37570)$ & $(0.07957)$ & $(0.22562)$ & $(0.93620)$ & $(0.03304)$ \\
\hline & {$[0.17214]$} & [ 12.3279] & {$[0.52391]$} & {$[0.13848]$} & [ 4.07642] \\
\hline \multirow[t]{3}{*}{$\operatorname{LRM}(-1)$} & -0.800980 & -0.186581 & 0.024630 & -0.291306 & -0.014452 \\
\hline & (1.88388) & $(0.06310)$ & $(0.17892)$ & $(0.74239)$ & $(0.02620)$ \\
\hline & {$[-0.42517]$} & {$[-2.95697]$} & {$[0.13766]$} & {$[-0.39239]$} & {$[-0.55154]$} \\
\hline \multirow[t]{3}{*}{ LG_EXP(-1) } & -0.093404 & 0.004745 & 0.037249 & -0.029018 & 0.000419 \\
\hline & $(0.45903)$ & $(0.01537)$ & $(0.04359)$ & $(0.18089)$ & $(0.00638)$ \\
\hline & {$[-0.20348]$} & {$[0.30860]$} & [ 0.85444$]$ & {$[-0.16041]$} & [ 0.06562$]$ \\
\hline \multirow[t]{3}{*}{ LCPI(-1) } & 0.189926 & -0.245136 & -1.140688 & -0.723206 & 0.814923 \\
\hline & $(4.18810)$ & $(0.14028)$ & $(0.39775)$ & $(1.65042)$ & $(0.05825)$ \\
\hline & {$[0.04535]$} & {$[-1.74753]$} & {$[-2.86785]$} & {$[-0.43819]$} & [ 13.9890] \\
\hline \multirow[t]{3}{*}{$\mathrm{C}$} & 7.607390 & 3.760950 & 17.07185 & 12.50871 & -0.047368 \\
\hline & $(35.0757)$ & $(1.17482)$ & (3.33120) & (13.8224) & $(0.48789)$ \\
\hline & [ 0.21688] & [ 3.20129] & [ 5.12484] & [ 0.90496$]$ & {$[-0.09709]$} \\
\hline \multirow[t]{3}{*}{ @TREND } & 0.025425 & 0.014129 & 0.059981 & 0.063482 & 0.002334 \\
\hline & $(0.12964)$ & $(0.00434)$ & $(0.01231)$ & $(0.05109)$ & $(0.00180)$ \\
\hline & [0.19611] & [ 3.25378$]$ & [ 4.87150$]$ & [ 1.24256$]$ & [ 1.29413] \\
\hline R-squared & 0.529211 & 0.993753 & 0.979926 & 0.715566 & 0.998790 \\
\hline Adj. R-squared & 0.440938 & 0.992581 & 0.976162 & 0.662235 & 0.998563 \\
\hline Sum sq. resids & 17.76200 & 0.019926 & 0.160206 & 2.758336 & 0.003437 \\
\hline S.E. equation & 0.745025 & 0.024954 & 0.070756 & 0.293595 & 0.010363 \\
\hline F-statistic & 5.995174 & 848.3843 & 260.3440 & 13.41735 & 4403.135 \\
\hline Log likelihood & -40.00185 & 92.45747 & 51.81107 & -3.684388 & 126.7302 \\
\hline Akaike AIC & 2.410351 & -4.382435 & -2.298003 & 0.547917 & -6.140010 \\
\hline Schwarz SC & 2.708939 & -4.083847 & -1.999415 & 0.846505 & -5.841422 \\
\hline Mean dependent & 2.272298 & 8.626658 & 14.12115 & 6.968972 & 5.103946 \\
\hline S.D. dependent & 0.996417 & 0.289719 & 0.458275 & 0.505174 & 0.273408 \\
\hline \multicolumn{2}{|c|}{ Determinant resid covariance (dof adj.) } & $1.00 \mathrm{E}-11$ & & & \\
\hline \multicolumn{2}{|c|}{ Determinant resid covariance } & $3.72 \mathrm{E}-12$ & & & \\
\hline \multicolumn{2}{|c|}{ Log likelihood } & 236.4876 & & & \\
\hline \multicolumn{2}{|c|}{ Akaike information criterion } & -10.33269 & & & \\
\hline \multicolumn{2}{|c|}{ Schwarz criterion } & -8.839755 & & & \\
\hline \multicolumn{2}{|c|}{ Number of coefficients } & 35 & & & \\
\hline
\end{tabular}




\section{Appendix 2B: Stability}

Roots of Characteristic Polynomial

Endogenous variables: LO_GAP LNER LRM

LG_EXP LCPI

Exogenous variables: C @TREND

Lag specification: 11

Date: 05/03/20 Time: 17:47

\begin{tabular}{cl}
\hline Root & Modulus \\
\hline $0.902063-0.070412 \mathrm{i}$ & 0.904807 \\
$0.902063+0.070412 \mathrm{i}$ & 0.904807 \\
0.627866 & 0.627866 \\
$0.032058-0.082224 \mathrm{i}$ & 0.088253 \\
$0.032058+0.082224 \mathrm{i}$ & 0.088253 \\
\hline
\end{tabular}

No root lies outside the unit circle.

VAR satisfies the stability condition.

\section{Appendix 2C: Serial correlation}

VAR Residual Serial Correlation LM Tests

Date: 05/03/20 Time: 17:48

Sample: 2010Q1 2019Q4

Included observations: 39

\begin{tabular}{|c|c|c|c|c|c|c|}
\hline \multicolumn{7}{|c|}{ Null hypothesis: No serial correlation at lag $\mathrm{h}$} \\
\hline Lag & LRE* stat & $\mathrm{df}$ & Prob. & Rao F-stat & df & Prob. \\
\hline 1 & 22.41797 & 25 & 0.6115 & 0.889394 & $(25,86.9)$ & 0.6179 \\
\hline 2 & 23.23732 & 25 & 0.5637 & 0.925893 & $(25,86.9)$ & 0.5705 \\
\hline \multicolumn{7}{|c|}{ Null hypothesis: No serial correlation at lags 1 to $\mathrm{h}$} \\
\hline Lag & LRE* stat & df & Prob. & Rao F-stat & df & Prob. \\
\hline 1 & 22.41797 & 25 & 0.6115 & 0.889394 & $(25,86.9)$ & 0.6179 \\
\hline 2 & 67.60708 & 50 & 0.0491 & 1.460599 & $(50,85.5)$ & 0.0616 \\
\hline
\end{tabular}

*Edgeworth expansion corrected likelihood ratio statistic. 


\section{Appendix 2D: Heteroskedasticity}

VAR Residual Heteroskedasticity Tests (Levels and Squares)

Date: 05/03/20 Time: 17:48

Sample: 2010Q1 2019Q4

Included observations: 39

\begin{tabular}{|c|c|c|c|c|c|}
\hline \multicolumn{6}{|c|}{ Joint test: } \\
\hline \multicolumn{2}{|c|}{ Chi-sq } & \multicolumn{2}{|c|}{ df } & \multicolumn{2}{|c|}{ Prob. } \\
\hline \multicolumn{2}{|c|}{210.8914} & \multicolumn{2}{|c|}{180} & \multicolumn{2}{|c|}{0.0573} \\
\hline \multicolumn{6}{|c|}{ Individual components: } \\
\hline Dependent & R-squared & $\mathrm{F}(12,26)$ & Prob. & Chi-sq(12) & Prob. \\
\hline res1*res1 & 0.974764 & 83.69070 & 0.0000 & 38.01581 & 0.0002 \\
\hline res $2 *$ res 2 & 0.372244 & 1.284782 & 0.2847 & 14.51752 & 0.2689 \\
\hline res $3 *$ res 3 & 0.492016 & 2.098559 & 0.0553 & 19.18862 & 0.0841 \\
\hline res4*res4 & 0.201814 & 0.547821 & 0.8626 & 7.870733 & 0.7951 \\
\hline res5*res5 & 0.458482 & 1.834433 & 0.0949 & 17.88081 & 0.1194 \\
\hline res $2 *$ res 1 & 0.418901 & 1.561900 & 0.1652 & 16.33714 & 0.1763 \\
\hline res3*res 1 & 0.451062 & 1.780346 & 0.1060 & 17.59140 & 0.1287 \\
\hline res $3 *$ res 2 & 0.263985 & 0.777114 & 0.6681 & 10.29542 & 0.5901 \\
\hline res4*res1 & 0.753486 & 6.622544 & 0.0000 & 29.38594 & 0.0035 \\
\hline res4*res2 & 0.277010 & 0.830149 & 0.6204 & 10.80341 & 0.5458 \\
\hline res4*res3 & 0.186962 & 0.498235 & 0.8969 & 7.291513 & 0.8378 \\
\hline res5*res 1 & 0.160205 & 0.413329 & 0.9446 & 6.248009 & 0.9031 \\
\hline res $5 *$ res 2 & 0.295884 & 0.910480 & 0.5498 & 11.53949 & 0.4833 \\
\hline res5*res3 & 0.463218 & 1.869731 & 0.0883 & 18.06549 & 0.1137 \\
\hline res $5 *$ res 4 & 0.279763 & 0.841602 & 0.6101 & 10.91075 & 0.5366 \\
\hline
\end{tabular}

